\title{
Overview on conductometric solid-state gas dosimeters
}

\author{
I. Marr, A. Groß, and R. Moos \\ Department of Functional Materials, University of Bayreuth, Bayreuth, Germany \\ Correspondence to: R. Moos (functional.materials@uni-bayreuth.de)
}

Received: 1 August 2013 - Revised: 20 December 2013 - Accepted: 6 January 2014 - Published: 22 January 2014

\begin{abstract}
The aim of this article is to introduce the operation principles of conductometric solid-state dosimeter-type gas sensors, which have found increased attention in the past few years, and to give a literature overview on promising materials for this purpose. Contrary to common gas sensors, gas dosimeters are suitable for directly detecting the dose (also called amount or cumulated or integrated exposure of analyte gases) rather than the actual analyte concentration. Therefore, gas dosimeters are especially suited for low level applications with the main interest on mean values. The applied materials are able to change their electrical properties by selective accumulation of analyte molecules in the sensitive layer. The accumulating or dosimeter-type sensing principle is a promising method for reliable, fast, and long-term detection of low analyte levels. In contrast to common gas sensors, few devices relying on the accumulation principle are described in the literature. Most of the dosimeter-type devices are optical, mass sensitive (quartz microbalance/QMB, surface acoustic wave/SAW), or field-effect transistors. The prevalent focus of this article is, however, on solid-state gas dosimeters that allow a direct readout by measuring the conductance or the impedance, which are both based on materials that change (selectively in ideal materials) their conductivity or dielectric properties with gas loading. This overview also includes different operation modes for the accumulative sensing principle and its unique features.
\end{abstract}

\section{Introduction}

In times of strict environmental requirements and an increasing demand for mobility and energy, a growing need for reliable, low concentration level gas-sensing devices comes along. Especially the detection of toxic, harmful gases, like $\mathrm{SO}_{2}, \mathrm{NO}$ and/or $\mathrm{NO}_{2}\left(=\mathrm{NO}_{\mathrm{x}}\right), \mathrm{H}_{2} \mathrm{~S}, \mathrm{CO}$, or $\mathrm{NH}_{3}$, which can affect human health, particularly in workplaces and urban environments, are important target gases for gas sensors. Inexpensive sensor devices based on semiconducting metal oxides manufactured in ceramic technology or in thin- or thickfilm technology are installed in annual quantities of millions (Yamazoe, 2005). The measurand is the conductance of metal oxides, as it depends on the analyte concentration. For information on the physical background of such sensors, the reader is referred to reviews in the literature (Göpel, 1994; Williams, 1999; Kohl, 2001; Yamazoe et al., 2003; Barsan et al., 2007). Semiconducting solid-state gas sensors can be miniaturized and operated with low power consumption (Simon et al., 2001; Semancik et al., 2001). However, most sensors show poor selectivity, nonlinear characteristics (Williams, 1999; Yamazoe et al., 2003), and according to Padilla et al. (2010), the main drawback is their lack of stability over time, leading to recalibration costs. Another issue is that increased sensitivity is often accompanied by a slow sensor kinetic. Even if the response time is fast enough for special applications, in many cases the recovery time is not. This does not really jeopardize low-cost applications for detecting dangerous conditions or alarm concentration levels. If, however, maximum allowable concentrations in emission or immission regulations are given in time-weighted average concentrations or cumulated amounts, like the immission standards for air quality monitoring as annual or hourly mean values, a mathematical integration of the linearized sensor signal is error-prone due to both slow sensor recovery times and baseline drifts.

For instance, $\mathrm{NO}_{2}$ thresholds are given by the EU immission legislation Directive 2008 (Directive, 2008) or the German air quality standards (BImSchV, 2010) as an annual mean value of $40 \mu \mathrm{g} \mathrm{m}^{-3}$, a one-hour value of $200 \mu \mathrm{g} \mathrm{m}^{-3}$ that 
should not be exceeded more than 18 times per calendar year, and an alert limit of $400 \mu \mathrm{g} \mathrm{m}^{-3}$ measured over three consecutive periods of one hour each. For comparison, the one hour limit of $200 \mu \mathrm{g} \mathrm{m}^{-3} \mathrm{NO}_{2}$ corresponds to a concentration of $0.1 \mathrm{ppm}$. In order to detect such small integrated concentration values by conventional semiconducting gas sensors with the required accuracy, complex procedures like continuous switching between clean air and analyte are required (Schütze et al., 1995).

Solid-state dosimeter-type gas sensing principles comprise a promising method for overcoming the above-mentioned drawbacks. Like passive samplers, solid-state gas sensors working in the accumulating mode are adequate devices for the reliable detection of lowest pollution levels (Seethapathy et al., 2008) because the dosimeter principle eludes several problems of a conventional gas sensor (Yamazoe and Shimanoe, 2007).

There are various publications on sensing devices mentioning an "irreversible reaction" or a very slow recovery time, not recognizing the benefits of this sensor behavior that differs from conventional gas sensors. The intention of this overview is to show exemplarily research papers that observed accumulating, integrating or irreversible gas-sensing properties. Sensor responses that do not recover in the absence of analyte under sorption conditions are denoted as "irreversible" in the following, even if the samples can be regenerated under modified operation conditions. It is a further aim of this study to elucidate the sensing principle and some special operation modes that allow a direct readout of the concentration as well as an accumulated concentration value at the same time and a plausibility check during regeneration.

This overview lists the different dosimeter-type gas sensing principles using the change of the electrical properties of the gas-sensitive material as the measurand. The focus of this overview is on conductometric integrating gas sensors but there are also optical (mostly organic dye-based coloration reactions) (Dasgupta et al., 1998; Tanaka et al., 1998, 1999; Sasaki et al., 2001; Maruo, 2007; Maruo et al., 2009; Small et al., 2009; Bhalla et al., 2010), SAW (Martin et al., 1996; Nieuwenhuizen and Harteveld, 1997), field-effect transistors (FET) (Andringa et al., 2012; Klug et al., 2013), quartz microbalance (QMB) (Matsuguchi et al., 2005; Jung et al., 2009), and passive sampling (Roadman et al., 2003; Varshney and Singh, 2003; Seethapathy et al., 2008) devices that are able to detect very low gas concentrations in the ppb range.

This article reviews the basic working principles of conductometric solid-state gas dosimeters (Sect. 2). It considers the direct amount determination and the indirect concentration determination, influencing factors, and compares gas dosimeters with classical gas sensors. Certain basic examples for sensing devices using the dosimeter-type sensing principle are shown in Sect. 3. Section 4 describes modifications regarding the dosimeter setup and the operation modes. Fur- thermore, suitable or already applied materials are listed in Sect. 5 .

\section{Basic working principle of a solid-state gas dosimeter}

The basic working principle of gas dosimeters relies on the accumulation of analyte gas molecules in the sensitive layer of the detecting device and the concomitant accumulation level dependent change of the electrical properties. The irreversible, selective, and progressive analyte sorption resulting in analyte accumulation can be caused by strong analyte sorption or a chemical reaction between the analyte and the receptor. Hence, gas dosimeters working in the accumulation mode (Yamazoe and Shimanoe, 2007) are often also denoted as "integrating" or "accumulating" sensors (Tanaka et al., 1999; Maruo 2007; Shu et al., 2010; Geupel et al., 2010; Groß et al., 2012b). For the explanation of the accumulating sensing principle, a planar setup consisting of an insulating support with electrodes, e.g., interdigitated electrodes, covered with a sensitive layer, was chosen. This setup makes it possible to measure the conductance of the sensor layer.

\subsection{Direct amount and indirect concentration detection}

The benefit of the dosimeter-type sensing behavior is the direct determination of the dose of the analyte gas species or the mean concentration in a defined period of time without the need for a mathematical integration of the sensor signal. In the case of a constant gas flow rate, the analyte dose as the measurand can be given in a simplified manner as the analyte amount or cumulated exposure $A_{\mathfrak{c}}$, calculated according to Eq. (1) as the time integral of the analyte concentration $c(t)$ with the starting point of the sorption interval $t_{0}$ :

$A_{\mathrm{c}}=\int_{t_{0}}^{t} c(t) \mathrm{d} t$.

$A_{\mathrm{c}}$ is often given in the unit ppm s, which can be converted to $\mu \mathrm{L}$ or $\mu \mathrm{mol}$ if accounting for the applied gas flow rate.

The determination of the amount $A_{\mathrm{c}}$ as the measurand of the gas dosimeter is in accordance with national or international environmental immission or emission regulations, given, for instance, as mean time values, like the annual or $1 \mathrm{~h}$ limit.

Similar to passive samplers, the operation of dosimetertype gas sensors with an analyte sorbent as sensitive material can be divided into two alternating periods: the sensing or analyte sorption interval and the regeneration or analyte release step. The fundamental operation principle of an accumulating gas sensor is depicted schematically in Fig. 1. Under sorption conditions, the analyte gas is sorbed "irreversibly" by the sensitive sensor layer since the sorption rate is enhanced compared to the desorption rate, provoking the 
a)

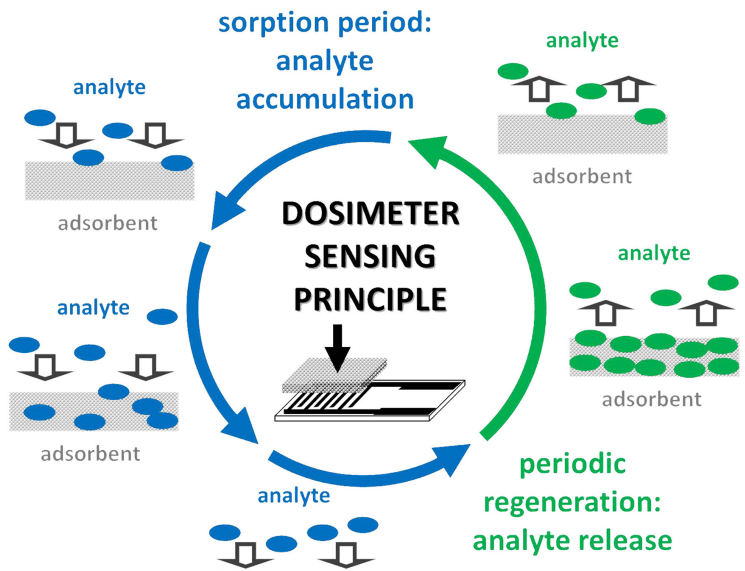

b)

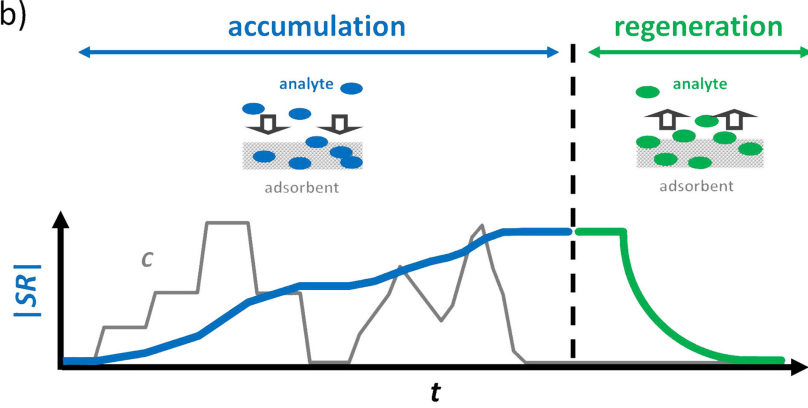

Figure 1. Scheme of the operation principle of a dosimeter-type gas sensing device with a sensitive layer as an adsorbent: (a) alternation of analyte accumulation in the sorption period (blue) and analyte release upon regeneration (green), (b) sensor response $|\mathrm{SR}|$ during the analyte accumulation (blue) and during the short-term regeneration period (green).

change of at least one material property due to analyte accumulation. In a short regeneration step under defined conditions, the formerly sorbed analyte molecules are released from the sorbent and the sorption capacity is recovered. Dependent on the interaction between the sorbent and the analyte, different regeneration procedures are effective to recover the sorption capacity as well as the sensor signal. They include thermal decomposition at elevated temperatures (Katayama et al., 2004; Helwig et al., 2008; Kubinski and Visser, 2008; Brunet et al., 2008; Shu et al., 2010; Brandenburg et al., 2013; Groß et al., 2013a), chemical reactions, e.g., by a changed gas atmosphere (Helwig et al., 2007, 2008; Groß et al., 2012a) or optical-induced desorption, e.g., by UV light (Li et al., 2003; Helwig et al., 2008).

As sketched in Fig. 1b, the absolute value of the accumulation-level dependent physical property that is monitored and evaluated as sensor response, $|\mathrm{SR}|$, increases during the sorption period and recovers during regeneration. "... the sensor is designed to provide an output that intrinsically depends on the history of the input quantities" (Angelini et al., 2009) and therefore the sensor response correlates with the cumulated exposure. Hence, the electrical detection of the analyte might occur either during the sorption or during the release period (Kubinski and Visser, 2008; Groß et al., 2013a). In the literature, this change in the accumulationlevel is detected mainly optically (Tanaka et al., 1999; Sasaki et al., 2001; Maruo, 2007) or gravimetrically (Matsuguchi et al., 2005). Recently impedimetric approaches have emerged (Varghese et al., 2001; Mattoli et al., 2007; Helwig et al., 2008; Geupel et al., 2010; Shu et al., 2010; Hennemann et al., 2012a; Groß et al., 2012c). Regeneration has to be initiated if saturation effects limit the sorption rate of the sensitive layer or if the sensing characteristic is deteriorated.

The dosimeter-type sensing properties are often demonstrated in two different ways, but always at a constant gas flow: first, by looking at the signal change as a function of the exposure duration at a constant analyte concentration; or secondly, by plotting the concentration-related characteristic line of the measured data after specific exposure duration. However, more information on the accumulating sensing properties is obtained by a repeated exposure to pulses of analyte gas with a defined concentration and duration.

A more detailed analysis of the ideal sensor response of a gas dosimeter with a linear sensing characteristic during the analyte sorption at a constant gas velocity is shown in Fig. 2. Like the cumulated amount, $A_{\mathrm{c}}$, being the time integral of the concentration according to Eq. (1), the absolute value of the sensor response, $|\mathrm{SR}|$, in Fig. 2a increases in the presence of the analyte gas. Thereby, the slope of the time-dependent sensor response reflects the sorption rate and correlates with the actual analyte concentration $c(t)$ (Dasgupta et al., 1998; Sasaki et al., 2001; Reyes et al., 2006; Shu et al., 2010; Groß et al., 2012a; Mukherjee et al., 2012). In the absence of the analyte, i.e., if $c=0 \mathrm{ppm}$, no signal recovery occurs, the sensor response remains constant and the response change due to the analyte is irreversible (Nieuwenhuizen and Harteveld, 1997). The course of $|\mathrm{SR}|$ in Fig. 2a indicates progressive analyte accumulation in the sensitive layer. Ideally, the sensor response $|\mathrm{SR}|$ depends linearly on the analyte amount, $A_{\mathrm{c}}$ (Fig. 2b). When the characteristic line becomes nonlinear, the sensitive layer needs to be regenerated. The amount sensitivity $S_{\mathrm{A}}$ is defined as the slope of the characteristic line in the linear measurement range.

In consequence of the concentration-dependent slope of the sensor response, the course of the current analyte concentration over time can be determined by the time derivative of the sensor response $|\mathrm{dSR} / \mathrm{d} t|$, as shown on the timescale in Fig. 2c. The corresponding concentration-related characteristic line with the concentration sensitivity $S_{\mathrm{c}}$ is depicted in Fig. 2d. Instead of the equilibrated state, in the case of gas dosimeters, the sensor response change is evaluated.

Figure 2 clarifies that with gas dosimeters two pieces of information can be obtained from just one sensitive device: the sensor response correlates directly and without mathematical signal operations with the cumulated analyte exposure, 


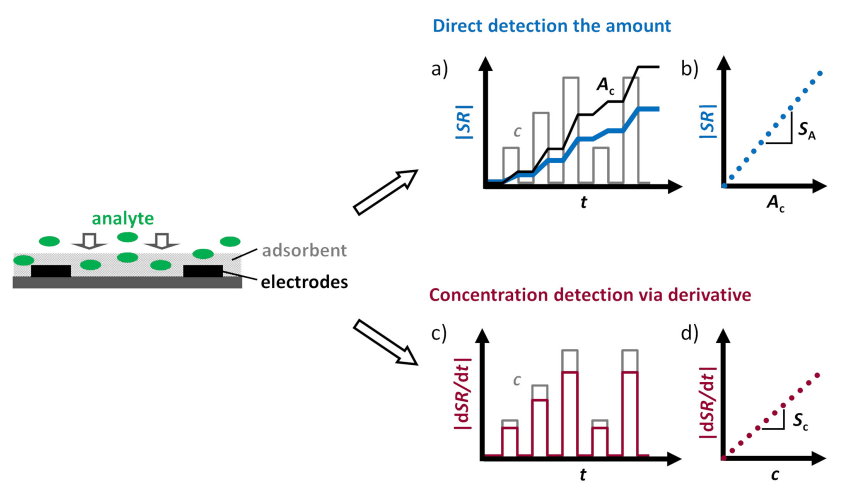

Figure 2. Dual-mode functionality of gas dosimeters: (a) correlation between the analyte amount $A_{\mathrm{c}}$ and the sensor response $|\mathrm{SR}|$ and (b) associated amount-related characteristic line, (c) correlation between the time-dependent analyte concentration $c(t)$ and the time derivative of the signal $|\mathrm{dSR} / \mathrm{d} t|$ and (d) associated concentrationrelated characteristic line.

and the current course of the analyte concentration can be determined indirectly from the signal derivative. For an ideal dosimeter, the material acts as an integrator and the derivative reflects the actual concentration. This is in contrast to an ideal classical gas sensor, which determines the actual concentration but the dose has to be obtained by integration.

The accumulating sensing principle is well suited for the long-term detection of very low analyte concentrations. By the chemical accumulation of the analyte molecules in the sensitive sorbent, the dosimeter "counts" every gas molecule that reaches the sensitive layer and causes a change of the physical properties of the material. This chemical integration increases the accuracy of the amount determination compared to conventional concentration detecting gas sensors. There, the determination of the average concentration values or the cumulated exposure by mathematical integration of the concentration-related sensor response is error-prone in the case of very low gas concentrations due to slow sensor kinetics, zero-point drifts and nonlinearities in the measurement range (Corcoran and Shurmer, 1994).

As described above, periodic regeneration recovers the sorption capacity of the sensitive layer as well as the sensor response. Concerning the observed saturation of gas dosimeters, e.g., in Geupel et al. (2010), it needs to be distinguished whether those effects originate from the limited number of sorption sites in the analyte sensitive material or from a nonlinear correlation between the sensor response and the analyte loading level.

\subsection{Influencing factors}

Similar to passive samplers, different sensor setup parameters and measurement conditions influencing the dosimetertype gas sensing properties are reported in the literature and will be summarized and discussed.
Like conventional sensors, gas dosimeters may show cross sensitivities to other gases if those interact with the sensitive layer. They might restrict or promote the analyte sorption process, which would affect the analyte sensitivity. Additionally, the sensor response might change reversibly (Varghese et al., 2001) or irreversibly due to other gas components dependent on the strength of interaction with the receptor. For instance, the dosimeter-type $\mathrm{NO}_{\mathrm{x}}$ sensing properties of a carbonate-based sensitive layer were found to be affected by $\mathrm{SO}_{2}$ in two ways: the competition between $\mathrm{SO}_{2}$ and $\mathrm{NO}_{\mathrm{x}}$ for the sorption sites lowers the $\mathrm{NO}_{\mathrm{x}}$ sensitivity as well as the measurement range. Furthermore, the conductivity is irreversibly affected by sulfate formation, enabling $\mathrm{SO}_{2}$ dosimetry (Groß et al., 2012d).

The analyte sorption properties of the sensitive material are also influenced by the operation temperature. Due to kinetic limitations, the sorption rate diminishes at lower temperatures; however, the strength of the analyte receptor interaction increases, resulting in accumulating properties due to a reduced desorption rate. With increasing temperature, analyte sorption occurs faster and the sensitivity is enlarged. However, since the sorption capacity is reduced and the strength of interaction is weakened, the sensitive layer tends to release formerly sorbed analyte molecules. Hence, higher temperatures increase the sensitivity of gas dosimeters but reduce the linear measurement range (Groß et al., 2012a).

While the equilibrated sensor response is monitored with conventional sensors as a measure of the analyte concentration, the progressive change of the material properties of gas dosimeters during analyte sorption serves as the measure of the cumulated amount. Hence, for the accumulating properties of the gas dosimeter it is very important that the chemical equilibrium is strongly shifted to the product side. Since the chemical equilibrium is strongly affected by temperature, it is possible that the same sensitive device can act like a gas dosimeter at low temperatures, while at higher temperatures it shows the typical concentration-related gas sensor behavior (Reyes et al., 2006; Shu et al., 2010; Andringa et al., 2012). Brandenburg et al., 2013 demonstrate this temperature-dependent behavior for a sensitive layer of a carbonate-based $\mathrm{NO}_{\mathrm{x}}$ storage material. The sensor shown in Fig. 3 acts as an accumulating-type gas sensor up to $450^{\circ} \mathrm{C}$, whereas the enhanced $\mathrm{NO}_{\mathrm{x}}$ desorption rate in the absence of analyte deteriorates the sensor response at $550{ }^{\circ} \mathrm{C}$. At $650^{\circ} \mathrm{C}$, response and recovery of the sensor signal to pulses of $\mathrm{NO}_{\mathrm{x}}$ are very fast and the sensor behaves like a concentration detecting device (Fig. 3c) (Brandenburg et al., 2013).

Another influencing factor is the thickness of the sensitive layer being related to the sorption capacity (Nieuwenhuizen and Harteveld, 1997; Shu et al., 2011). Groß et al. demonstrated the dependency of the dosimeter-type $\mathrm{NO}_{\mathrm{x}}$ sensing properties on the thickness of the carbonate-based sorbent. Since nitrates form mainly at the surface of the sorbent, the sensitivity of the $\mathrm{NO}_{\mathrm{x}}$ accumulating sensor decreases with a growing layer thickness as the linear measurement range 


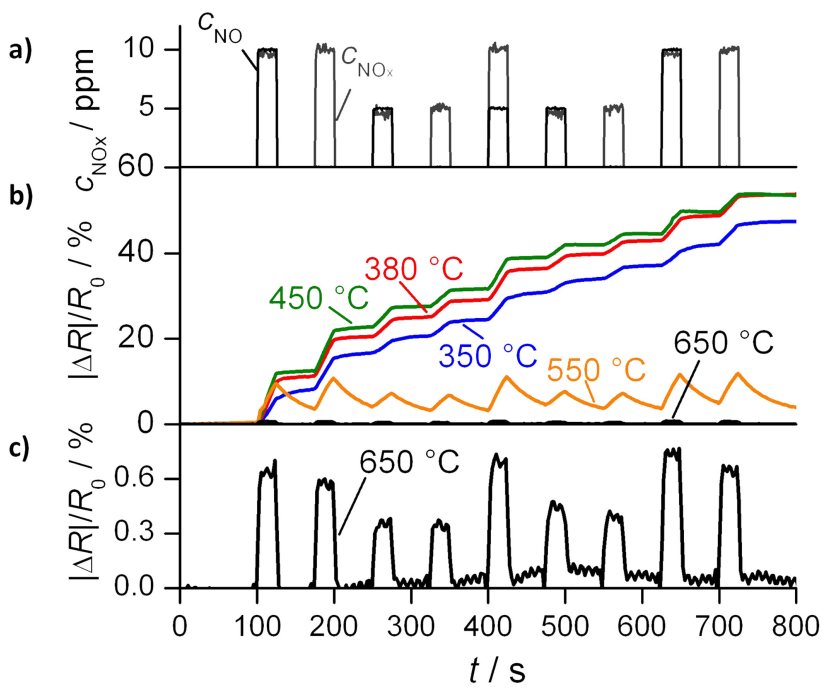

Figure 3. Temperature-dependence of the gas sensing behavior of a carbonate-based $\mathrm{NO}_{\mathrm{x}}$ storage material for $\mathrm{NO}_{\mathrm{x}}$ sensing purposes: (a) dosed $\mathrm{NO}_{\mathrm{x}}\left(\mathrm{NO}\right.$ or $\left.\mathrm{NO}_{2}\right)$ concentration, (b) sensor response $|\Delta R| / R_{0}=|\mathrm{SR}|$ for different temperatures and (c) sensor response at $650{ }^{\circ} \mathrm{C}$. Please note the different scale of the $y$ axes in (b) and (c). Reprinted from Brandenburg et al. (2013), with permission of Elsevier.

increases (Groß et al., 2012b). Additionally, the sensor response time concerning the concentration detecting properties was found to increase with the layer thickness.

Similarly, it is expected that the analyte uptake can be influenced by the sensitive surface area and hence the porosity of the sorbent.

As will be discussed in detail in Sect. 4, the setupdependent gas velocity across the sensitive material was found to affect the analyte sorption (Beulertz et al., 2011, 2012).

The main characteristics of the classical and the dosimetertype sensing principle - particularly for low level detection are briefly compared in Fig. 4.

Some further advantages of the dosimeter-type sensor principle should be mentioned here. The long-term zero drift, being a drawback of conventional gas sensors, is avoided by redefining the zero level at the end of each regeneration period.

While the sensors' response and recovery times, defined as the time span to reach the equilibrated states, are critical parameters for classical gas sensors, in the case of gas dosimeters the sensor signal change due to analyte accumulation is analyzed. Since the actual concentration value is given by the derivative, the sensor response is very fast.

It should also be mentioned that the measurement range and the sensitivity of the gas dosimeter can be adjusted during operation by varying the working temperature.
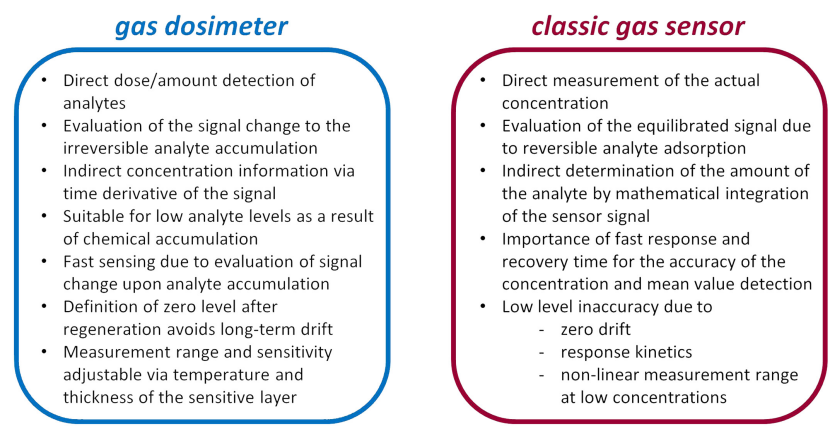

Figure 4. Comparison of the main features of a gas dosimeter for the long-term low-level analyte detection with the properties of a conventional gas sensor.

\section{Examples for conductometric gas dosimeters}

In the following, some work on conductometric or impedancemetric sensors working in the accumulation mode for different analytes and with various sensitive materials are discussed exemplarily.

Shu and colleagues presented a resistive $\mathrm{NO}_{2}$ sensor based on iron (II) phthalocyanine that is operated at room temperature (Shu, 2010; Shu et al., 2010, 2011). Figure 5 depicts the course of the measured resistance $R$ during cyclic exposure to $\mathrm{NO}_{2}$ for $30 \mathrm{~min}$ in concentrations of $0.5,1$, and $2 \mathrm{ppm}$. The total flow rates were $0.95,0.43$, and $0.25 \mathrm{~L} \mathrm{~min}^{-1}$, respectively. For all applied concentrations, the typical curve shape of a dosimeter-type gas sensor signal is observed. While dosing $\mathrm{NO}_{2}$ in $\mathrm{N}_{2}$ with a constant concentration, the resistance decreases with a steady slope and remains at its level during the intermediate $\mathrm{N}_{2}$ phases, resulting in plateaus in the response course. Unfortunately, the effect of $\mathrm{NO}_{2}$ is relatively low $\left(R / R_{0} \approx 1\right.$ to 0.88$)$ and the characteristic line is not linear. The regeneration of this $\mathrm{NO}_{2}$ chemo-dosimeter is achieved thermally. The influence of the temperature was investigated in the range from $-46^{\circ} \mathrm{C}$ to $71^{\circ} \mathrm{C}$. For the difference of $\sim 50^{\circ} \mathrm{C}$ the resistance decreases approximately one order of magnitude. With increased temperature the desorption effects increase. Regarding the long-term stability, an increase of the conductivity during storage in air due to the adsorption of $\mathrm{H}_{2} \mathrm{O}$ and $\mathrm{O}_{2}$, an effect which is known for metal containing phthalocyanines, can be observed (Shu, 2010).

Helwig et al. realized a dosimeter-like p-type conductometric gas sensor with a hydrogenated diamond (HD) as $\mathrm{pH}$ sensitive material for $\mathrm{NO}_{2}$ and $\mathrm{NH}_{3}$ as analytes (Beer et al., 2013; Helwig et al., 2013). Figure 6 compares the resistance changes of the HD-sample to those of a conventional metal oxide (MOX)-based device in dry synthetic air. Due to the electrolytic dissociation of the gases in the sensitive layer, the resistance at room temperature decreases stepwise in the presence of $\mathrm{NO}_{2}$ pulses (Fig. 6a, red line) and increases in the $\mathrm{NH}_{3}$-containing atmosphere (Fig. 6b, red line). For both analytes, the sensitive hydrogenated diamond device works 


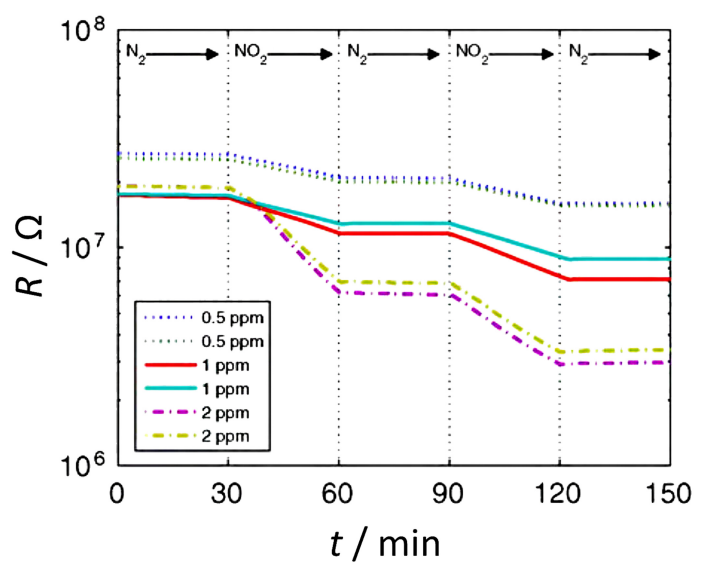

Figure 5. Course of the resistance $R$ of iron(II)phthalocyanine in the presence of different $\mathrm{NO}_{2}$ concentrations at room temperature. Adapted from Shu et al. (2010); reprinted with permission from Elsevier.

like an integrator-like gas sensor, whereas the signal of the metal oxide-based gas sensor (black line) shows the expected behavior of a conventional concentration related gas sensor. The recovery times of the dosimeter can be enhanced by a temperature increase, or by ozone or UV light. Figure $6 \mathrm{c}$ shows the reset of the sensor response after exposure to $\mathrm{NH}_{3}$ in different concentrations by a short $\mathrm{O}_{3}$ pulse after each ammonia phase, causing the oxidation of $\mathrm{NH}_{3}$ at the sensor surface at room temperature (Helwig et al., 2008).

In another example, a lean $\mathrm{NO}_{\mathrm{x}}$-trap material known from automotive $\mathrm{NO}_{\mathrm{x}}$ storage catalysts was applied as the $\mathrm{NO}_{\mathrm{x}}$ sensitive layer (Geupel et al., 2010, 2011). At $380^{\circ} \mathrm{C}$, the carbonate-based material accumulates $\mathrm{NO}$ and $\mathrm{NO}_{2}$ chemically by forming nitrates. Due to nitrate formation, the resistance decreases, enabling total $\mathrm{NO}_{\mathrm{x}}$ dosimetry. Figure 7 demonstrates the suitability of the carbonate-based dosimeter for the long-term detection of $\mathrm{NO}_{2}$ even in the sub-ppm range. The sensor response $|\mathrm{SR}|=|\Delta R| / R_{0}$ in Fig. 7a follows the characteristic behavior of an accumulating gas sensor during cyclic exposure to 0.2 to $2 \mathrm{ppm} \mathrm{NO}_{2}$ in steps of $75 \mathrm{~s}$ over $50 \mathrm{~min} .|\Delta R| / R_{0}$ completely overlaps with the normalized time integral of the concentration, $\int c_{\mathrm{NO}_{2}}(t) \mathrm{d} t$ (with $c_{\mathrm{NO}_{2}}(t)$ calculated from mass flow controller output data), which is shown in green as a reference for the course of the cumulated amount. The corresponding characteristic line gives a linear correlation between the sensor response $|\Delta R| / R_{0}$ and the analyte amount $A_{\mathrm{NO}_{2}}$ (Fig. 7b). Due to this linearity, the time derivative of the resistance $|\mathrm{d} R / \mathrm{d} t|$ reflects the course of the $\mathrm{NO}_{2}$ concentration, as shown in Fig. 7c. In accordance with the European air quality standards limit of $200 \mu \mathrm{g} \mathrm{m}^{-3} \mathrm{NO}_{2}(\approx 0.1 \mathrm{ppm})$ and the applied flow rate of $2 \mathrm{~L} \mathrm{~min}^{-1}$, this hourly threshold of about $360 \mathrm{ppm} \mathrm{s}$ could be monitored for at least $3.7 \mathrm{~h}$ with the sensitivity of the $\mathrm{NO}_{\mathrm{x}}$ dosimeter shown in Fig. 7b, whereas it is even $18.5 \mathrm{~h}$ for the annual value of $40 \mu \mathrm{g} \mathrm{m}^{-3}$. Besides the sensitivity, the lin- ear measurement range of the presented sensor was found to be affected by temperature (Geupel et al., 2011) as well as by the thickness (Groß et al., 2012b) of the sensitive layer. The linear range always ends at a sensor response change of about 30 to $40 \%$. Regeneration is achieved by increasing the temperature to $650^{\circ} \mathrm{C}$ (Groß et al., 2013a) or switching to reducing gas atmospheres (Geupel et al., 2010).

Further examples for resistive-type gas dosimeters will be given in the next sections with the focus on modifications of the gas dosimeter setup and with special respect to the operation mode as well as to suitable sorbent materials.

\section{Modifications of the dosimeter principle}

Several conductometric sensors relying on the accumulating detection principle are reported. In this section, examples for modifications of the above-described dosimeter-type sensing principle are summarized. First of all, different configurations of the sensor setup and the associated influencing factors are described before discussing alternative operation modes.

\subsection{Dosimeter setup configurations}

The access of the analyte molecules to the sensitive layer, impacting the sensing properties particularly in the case of gas velocity fluctuations, can be varied by the gas dosimeter setup. Equation (1) defines the concentration-related amount of analyte $A_{\mathrm{c}}$ in the gas phase as the time integral of the concentration. However, for fluctuating flow rates, the analyte dose is better reflected by the volume-related amount $A_{\mathrm{V}}$ as the time integral of the concentration and the gas flow rate $\dot{V}(t)$ according to Eq. (2):

$A_{\mathrm{V}}=\int_{t_{0}}^{t} c(t) \cdot \dot{V}(t) \mathrm{d} t$.

If $\dot{V}(t)$ denotes a volume flow $\left([\dot{V}(t)]=\mathrm{m}^{3} \mathrm{~s}^{-1}\right)$, the unit of $A_{\mathrm{V}}$ is $\mathrm{m}^{3}$ (or here $\mu \mathrm{L}$ ). If, however, $\dot{V}(t)$ is a molar flow $([\dot{V}(t)]=$ $\mathrm{mol} \mathrm{s}^{-1}$ ), then the unit of $A_{\mathrm{V}}$ is mol, i.e., [ $\left.A_{\mathrm{V}}\right]=$ mol. Hence, the sensor signal of real amount-integrating gas dosimeters is expected to depend on the gas velocity. Otherwise the sensitive device works as a concentration integrator, allowing for concentration information by analyzing the signal derivative (Sect. 2.1).

Beulertz et al. (2011) investigated the influence of the flow rate on the sensor response of a carbonate-based $\mathrm{NO}_{\mathrm{x}}$ dosimeter. Figure $8 \mathrm{a}$ depicts the time course of the sensor response $|\mathrm{SR}|=|\Delta R| / R_{0}$ of the $\mathrm{NO}_{\mathrm{x}}$ dosimeter in the planar sensor setup at various flow rates. Exposed to the same analyte concentration profile, the sensor response of the planar sensor with a sensitive area of $42 \mathrm{~mm}^{2}$ placed in a quartz tube with an inner diameter of $9.2 \mathrm{~mm}$ increases - but independently of the gas flow rate, ranging from 200 

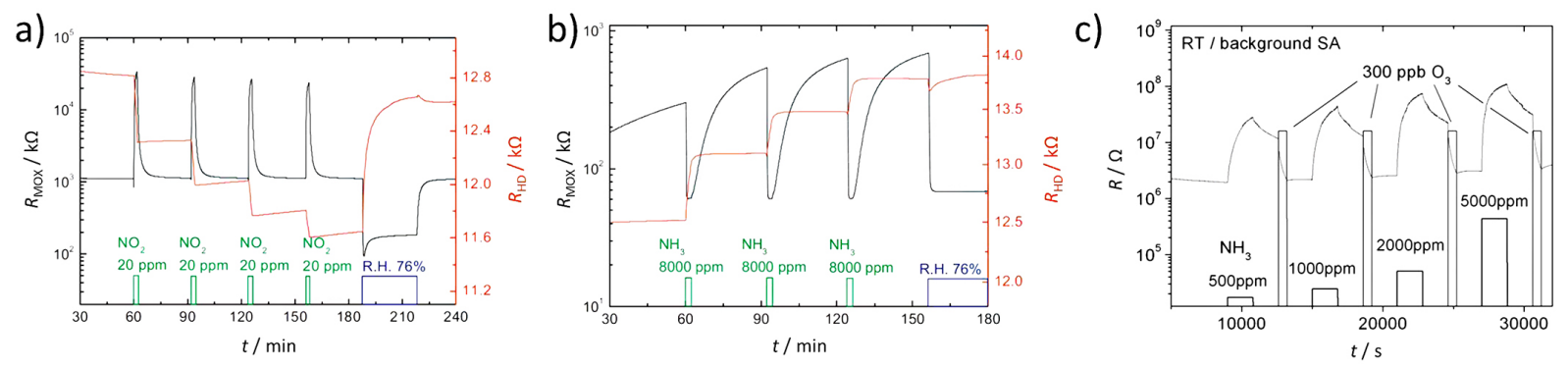

Figure 6. Dosimeter-like response of a hydrogenated diamond (HD) sensor at room temperature acting as pH sensor towards a sequence of (a) $\mathrm{NO}_{2}$ and (b) $\mathrm{NH}_{3}$ pulses in dry synthetic air and the effect of humidity. Adapted from Helwig et al. (2013); reprinted with permission from Elsevier. (c) Response of a hydrogenated diamond sample in synthetic air $\left(80 \% \mathrm{~N}_{2} / 20 \% \mathrm{O}_{2}\right.$ ) towards pulses of $\mathrm{NH}_{3}$ and the $\mathrm{O}_{3}$-induced reset of the sensor surface by $\mathrm{NH}_{3}$ oxidation. Modified after Helwig et al. (2008); reprinted with permission from Elsevier.

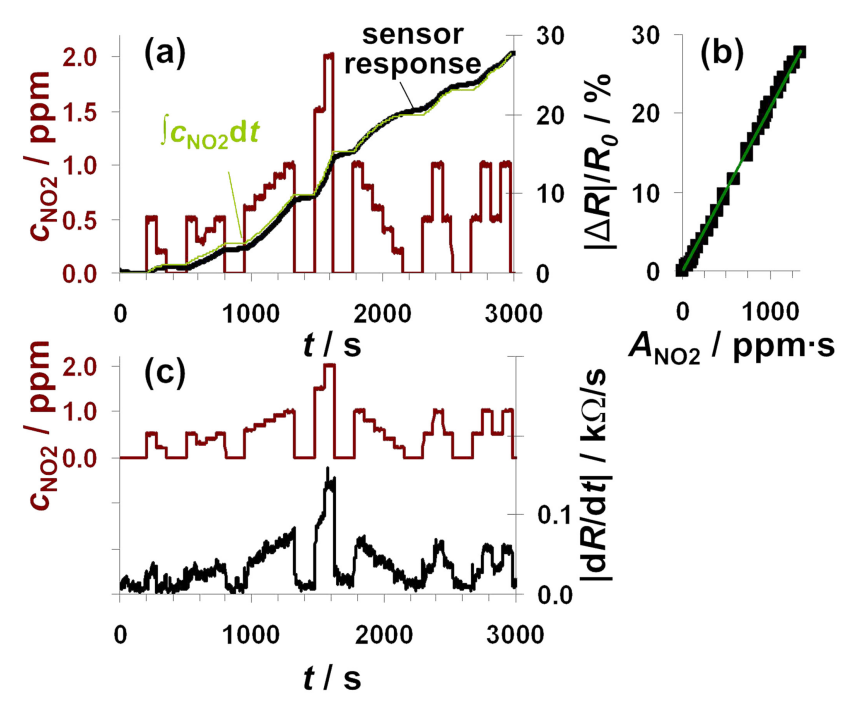

Figure 7. Suitability for the long-term low-level $\mathrm{NO}_{2}$ detection of a planar sensor with a carbonate-based LNT-material in lean atmosphere at $350^{\circ} \mathrm{C}$ : (a) sensor response $|\mathrm{SR}|=|\Delta R| / R_{0}$ in 0.2 to $2 \mathrm{ppm}$ $\mathrm{NO}_{2}$ for $75 \mathrm{~s}$ each, (b) linear correlation of $|\mathrm{SR}|=|\Delta R| / R_{0}$ and the total $\mathrm{NO}_{2}$ amount $A_{\mathrm{NO}_{2}}$, and (c) time derivative of the resistance $|\mathrm{d} R / \mathrm{d} t|$ follows the course of the $\mathrm{NO}_{2}$ concentration. Adapted from Groß et al. (2012a), with permission of the authors.

to $400 \mathrm{~mL} \mathrm{~min}^{-1}$. The corresponding characteristic lines in Fig. 8b, correlating the sensor response with the volumerelated amount $A_{\mathrm{V}}$ (here denoted as $A_{\mathrm{NO}}$ ), reveal that for the same total amount of NO in the gas stream, the sensor response $|\mathrm{SR}|=|\Delta R| / R_{0}$ differs for the applied gas flow rates. This implies that a planar gas dosimeter measures the integral of the concentration $A_{\mathrm{c}}$ independently of the gas flow rate, according to Eq. (1), and not the real, gas velocity-dependent amount of the analyte gas, $A_{\mathrm{V}}$, according to Eq. (2). This behavior can be explained by the fact that the gas velocity is very high and that only a small fraction of the gas stream passing the setup reaches the sensitive layer to be accumulated. In the investigated flow rate range, the analyte con- centration near the sensitive layer is always constant and unaffected by the sorption capability of the sensitive material, resulting in same sensor responses independent of the gas velocity.

For further investigations on the $\mathrm{NO}_{\mathrm{x}}$ dosimeter, a flowthrough channel-type sensor, as sketched in Fig. 9a, was developed in order to obtain full analyte storage (Beulertz et al., 2012; Moos et al., 2012). Due to the use of two sensitive layers with bigger sensitive areas of $126 \mathrm{~mm}^{2}$ (threefold longer compared to planar setup) with a small spacing in between, the diffusion of the passing analyte molecules to the sorption sites should be enhanced. The applied gas flow rate was adapted to the new geometry in such a way that the gas velocities across the sensitive layers were the same as in the planar setup. Hence, the measurements were carried out at flow rates of 30 to $60 \mathrm{~mL} \mathrm{~min}^{-1}$. All these modifications yielded a residence time of $151 \mathrm{~ms}$, a value which is in the same order of magnitude as in the small channels of an automotive lean $\mathrm{NO}_{\mathrm{x}}$ catalyst, in which one can observe a full storage without $\mathrm{NO}_{\mathrm{x}}$ slip. A second channel-type sensor was located downstream of the first dosimeter to detect the $\mathrm{NO}_{\mathrm{x}}$ slip. The sensor responses $|\mathrm{SR}|$ of the two channel-type sensors upon various NO concentrations and for the different flow rates are summarized in Fig. 8c. The response of the downstream sensor ("second sensor") remains zero for all runs. This indicates that for all applied flow rates, NO is completely sorbed by the sensitive layer of the first channeltype dosimeter. Comparing the sensor responses of the first sensor, a clear dependence of the sensor response on the gas flow rate for this channel-type setup appears. The higher the gas flow rate and, consequently, the higher the total exposed NO dose is, the higher is the sensor response. The characteristic lines demonstrate that in fact the same volume-related amount of analyte gas in the gas stream causes the same sensor response change. The sensitivity is independent of the gas velocity (in Fig. $8 \mathrm{~d}, A_{\mathrm{V}}$ denoted as $A_{\mathrm{NO}}$ ). Hence, the channeltype sensor setup can be used to establish a real amount integrating gas sensor, whereas the simple planar setup serves as concentration integrator with the benefit of a correlation 

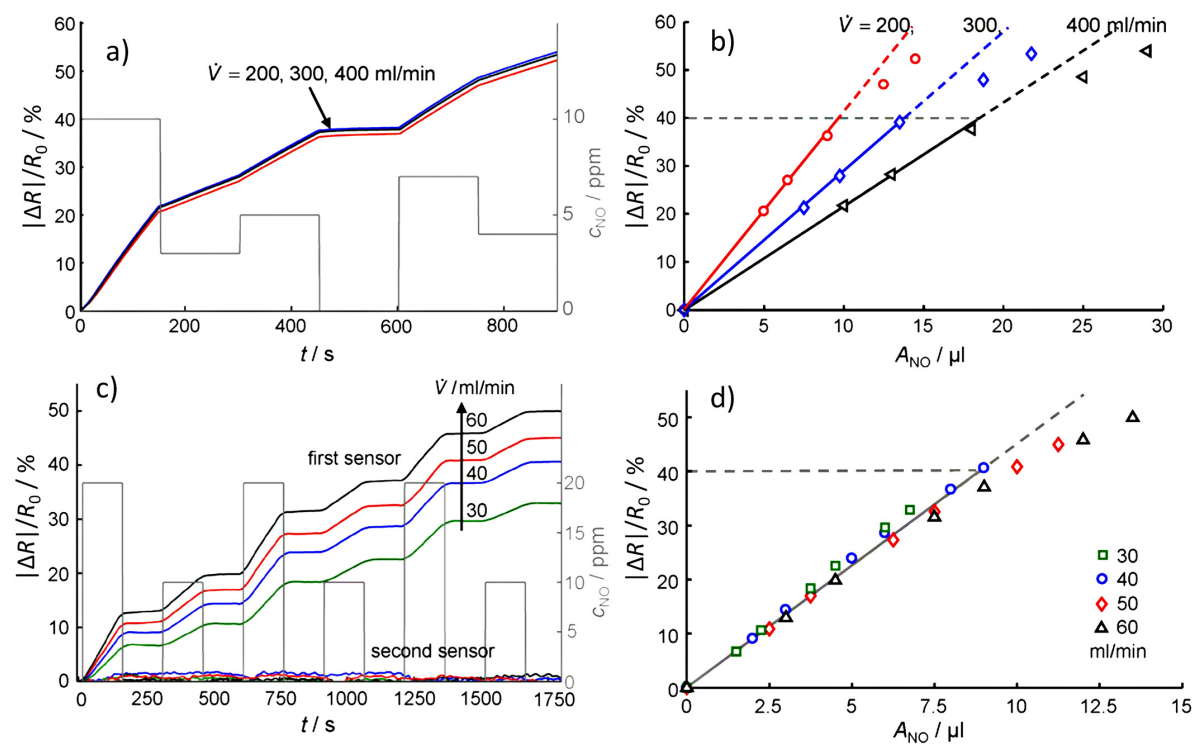

Figure 8. (a) and (b) Sensor response $|\mathrm{SR}|=|\Delta R| / R_{0}$ of a planar $\mathrm{NO}_{\mathrm{x}}$ accumulating sensor at various gas flow rates: (a) $|\mathrm{SR}|$ does not depend on the flow rates upon exposure towards 0 to $10 \mathrm{ppm} \mathrm{NO}$, (b) corresponding characteristic lines related to the flow rate-dependent total amount $A_{\mathrm{V}}$, here denoted as $A_{\mathrm{NO}}$. (c) and (d) Sensor response $|\mathrm{SR}|=|\Delta R| / R_{0}$ of a channel-type $\mathrm{NO}_{\mathrm{x}}$ accumulating senor at various gas flow rates: (c) course of $|\mathrm{SR}|$ in 0 to $20 \mathrm{ppm} \mathrm{NO}$ for the different flow rates, (d) corresponding characteristic lines related to the flow rate-dependent total amount $A_{\mathrm{V}}$, here denoted as $A_{\mathrm{NO}}$. Slightly modified after Beulertz et al. (2012); reprinted with permission from Elsevier.

a)
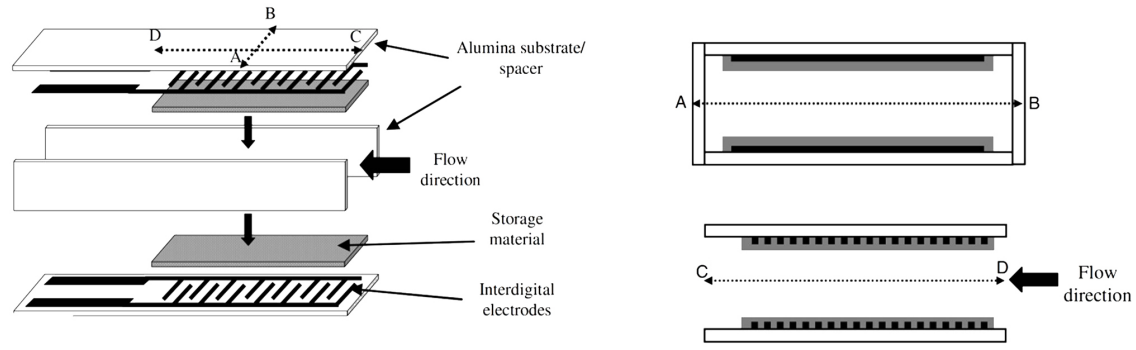

b)

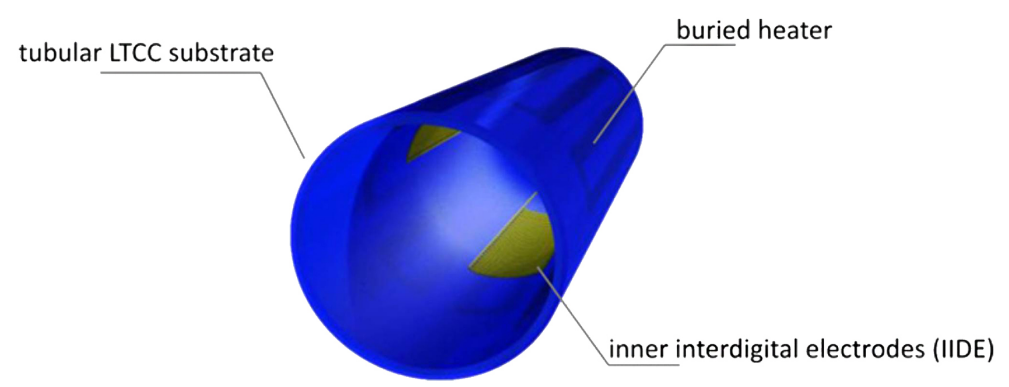

Figure 9. Scheme of setups of resistive gas dosimeters to obtain a flow rate-dependent analyte sorption. (a) Channel-type sensor setup with coated interdigital electrodes (IDE). Reprinted from Beulertz et al. (2011), with permission from Elsevier. (b) Tube-type LTCC transducer with a buried heater and coated inner interdigital electrodes (IIDE). Reprinted from Brandenburg et al. (2013), with permission from Elsevier. 
between the sensor response derivative and the actual concentration. A typical application of a concentration integrating dosimeter might be in the field of health protection for working people or air quality monitoring where the sensing device must be independent of the gas flow rate, while the amount integrating dosimeter is an appropriate tool in exhaust lines where the gas flow rate changes rapidly.

In a further development, a tubular, low temperature cofired (LTCC)-based $\mathrm{NO}_{\mathrm{x}}$ sensor setup with a buried heater structure was established (Fig. 9b) (Kita et al., 2012). Due to this rotational symmetric setup, the analyte can be sorbed uniformly by a sensitive layer deposited onto the inner surface of the tube. The enhanced interface between the gas phase and the sorbent also enables integrating sensing properties with linear characteristics concerning the volumerelated amount. The buried heater structure allows a uniform and adjustable temperature distribution in the sensitive layer as well as periodic switching between the sorption and the regeneration temperature (Brandenburg et al., 2013).

Another design of a gas dosimeter, similar to the setup of passive sampling devices, was introduced by Mattoli et al. (2007) for a mercury sensor with a gold layer as sorbent. As shown in Fig. 10a, the sensitive layer is located inside a sampling chamber closed by a filter material functioning as diffusion barrier. To reach the sensitive sorbent layer, the gas needs to diffuse through the filter, resulting in a gradient of the analyte concentration (here $\mathrm{Hg}$ ) between zero at the sorbent (acting as analyte sink) and the surrounding gas concentration (Fig. 10b). Hence, the uptake of the analyte in the sorbent is diffusion controlled, leading to an analyte current that depends linearly on the analyte concentration in the ambience. The independency of the analyte uptake on the velocity of the passing gas stream results in concentration integrating properties of the sensing device. Upon exposure to gaseous elemental $\mathrm{Hg}$, the dosimeter changes its sensor signal irreversibly. With growing number of mercury injections, the total amount of adsorbed $\mathrm{Hg}$ is concomitantly increased, which is reflected by the sensor signal. With this sensor design, real-time monitoring of low levels of gaseous analyte is possible with a small size, low weight and low cost device applicable for personal safety.

Different options for the arrangement of gas dosimeters in gas pipes are possible to decrease the gas velocity across the sensitive layer, for instance to place the sensing device in a bypass with or without a gas pump to ensure a constant gas stream (Moos et al., 2010).

\subsection{Operation modes of gas dosimeters}

As discussed, the proportionality between sensor signal and cumulated analyte amount of linear gas dosimeters allows for time-continuous direct dose detection during the sorption period and, depending on the setup, for concentration information by analyzing the signal derivative. However, gas dosimeters might also be operated in different modes. Some a)
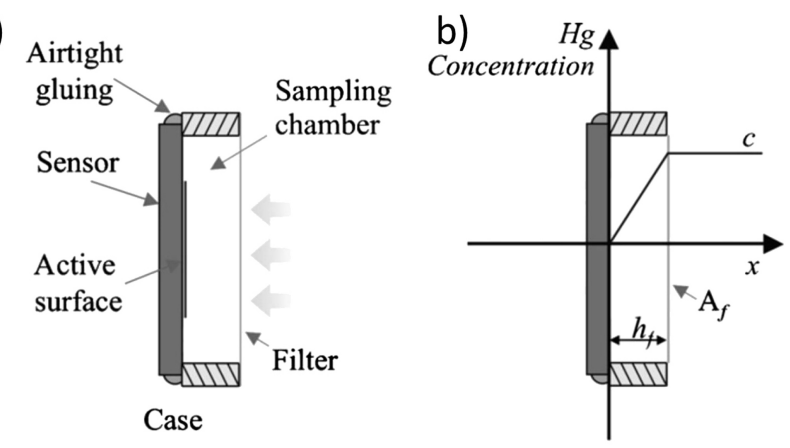

c)
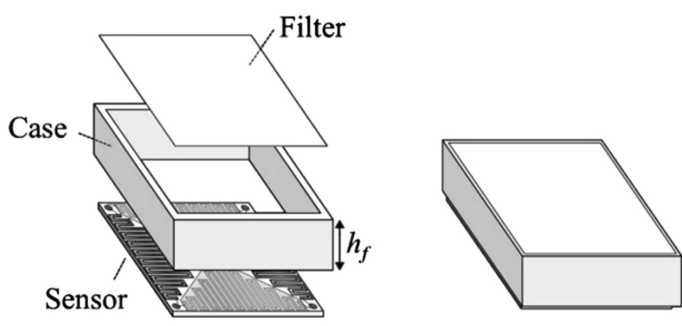

Figure 10. Gas dosimeter setup for a diffusion-controlled analyte sorption: (a) cross-section of the dosimeter sampling chamber with a filter acting as diffusion layer, (b) profile of the resulting $\mathrm{Hg}$ concentration, and (c) top view of the sampling chamber. Reprinted from Mattoli et al. (2007), with permission from Elsevier.

examples are described in the following. A summary concludes this section.

As described above and depicted in Fig. 1b, the analyte accumulation level of the sorbent is reflected by the electrical properties during the sorption period as well as during the subsequent analyte release in the regeneration interval. Hence, the analysis of the sensor signal change during the regeneration interval is another method for operating gas dosimeters. It was demonstrated on a potassium and manganese containing $\mathrm{NO}_{\mathrm{x}}$ sensor that, after the sorption period under sorption conditions, the change of the electrical conductance during thermal decomposition of the formerly formed nitrates correlates with the preceding sorbed analyte amount (Groß et al., 2013a). A schematic drawing of this novel method is given in Fig. 11. Since it combines electrical characterization of the sorbent with temperature programmed desorption of the analyte, it is also denoted as eTPD. Due to the heating from the sorption to the desorption temperature, the thermal activated conductance $G$ of the sensitive layer increases as well (Fig. 11b). Thereby, the conductance of the material in the $\mathrm{NO}_{\mathrm{x}}$ loaded state, $G$, exceeds those of the unloaded sample, $G_{0}$. The thermal release of the formerly sorbed analyte is indicated by a desorption peak with the concentration $c_{\text {released }}$ (measurable by an $\mathrm{NO}_{\mathrm{x}}$ analyzer downstream of the sensor). Upon this thermal release, the curve of the conductance of the sensitive layer in the analyte-loaded state, $G$, converges to those in the unloaded state, $G_{0}$ (Fig. 11a). The monitored desorption peak and the 


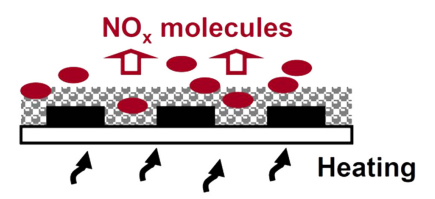

a)

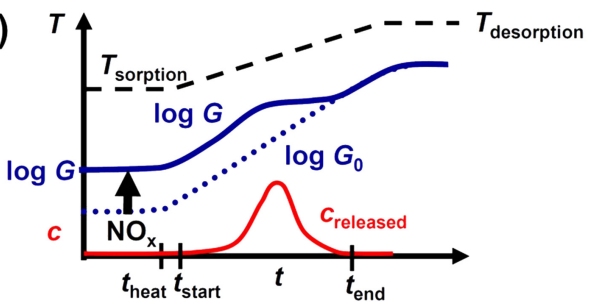

b)

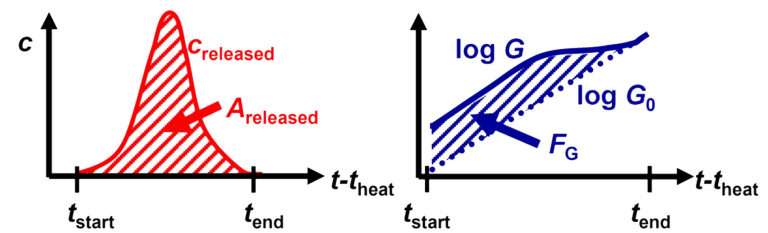

c)

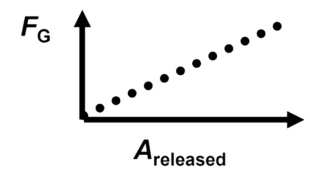

Figure 11. Scheme of the electrical evaluation during thermal regeneration (denoted as eTPD): (a) time dependence of the conductance $G$ and the outlet analyte concentration $c_{\text {released }}$ upon heating from the sorption to the regeneration temperature, (b) determination of the released amount $A_{\text {released }}$ from the desorption peak and the electrical response $F_{\mathrm{G}}$ as deviation of $G$ from the course of the unloaded state, and (c) analysis of $F_{\mathrm{G}}$ as a function of $A_{\text {released }}$. Reprinted from Groß et al. (2013a), with permission of the authors.

course of the conductance can be analyzed, as sketched in Fig. 11b. The desorption peak gives information on the formerly sorbed analyte amount, being equal to the released amount $A_{\text {released }}=\int c_{\text {released }} \mathrm{d} t$ if the regeneration is complete. The deviation of the thermally activated conductance after $\mathrm{NO}_{\mathrm{x}}$ loading, $G$, from the course in the unloaded state, $G_{0}$ (Fig. 11b), was evaluated as sensor signal during the regeneration interval (Fig. 11c) and is defined as $F_{\mathrm{G}}$ according to Eq. (3). Figure 11c depicts the dependency of the resulting sensor signal, $F_{\mathrm{G}}$, and the released analyte amount, $A_{\text {released }}$.

$F_{\mathrm{G}}=\int_{t_{\text {start }}}^{t_{\text {end }}}\left[\log G(t)-\log G_{0}(t)\right] \mathrm{d} t$.

Figure 12 summarizes the results of an eTPD analysis of the potassium and manganese containing $\mathrm{NO}_{\mathrm{x}}$ dosimeter operated at a sorption temperature of $380^{\circ} \mathrm{C}$ and heated to $650{ }^{\circ} \mathrm{C}$ for thermal regeneration. During both intervals, the sensor was applied to a lean gas mixture of $2 \mathrm{~L} \mathrm{~min}^{-1}$. To achieve different $\mathrm{NO}_{\mathrm{x}}$ loading levels, the sensor sample was exposed to $8 \mathrm{ppm} \mathrm{NO}$ or $8 \mathrm{ppm} \mathrm{NO}_{2}$ for a duration $t_{\mathrm{NO}_{\mathrm{x}} \text {, in }}$ between $0 \mathrm{~s}$ and $1000 \mathrm{~s}$. The $\mathrm{NO}_{\mathrm{x}}$ loading level, evaluated as the a)

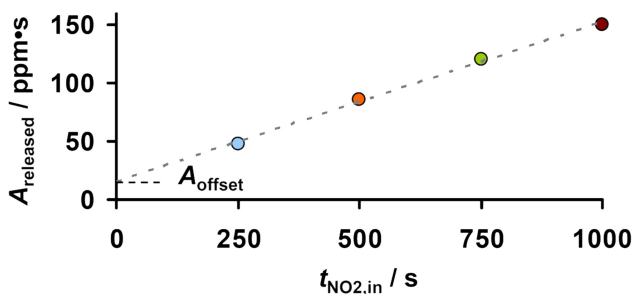

b)

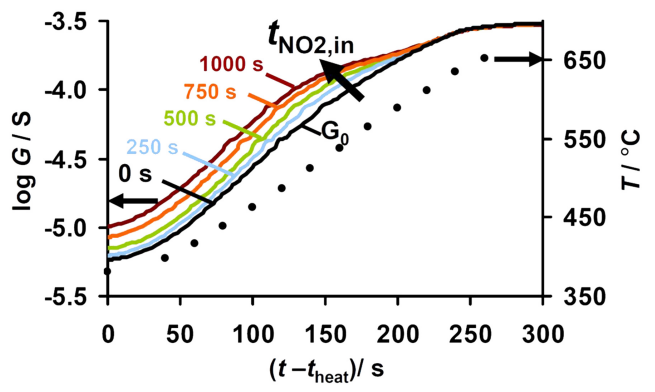

c)

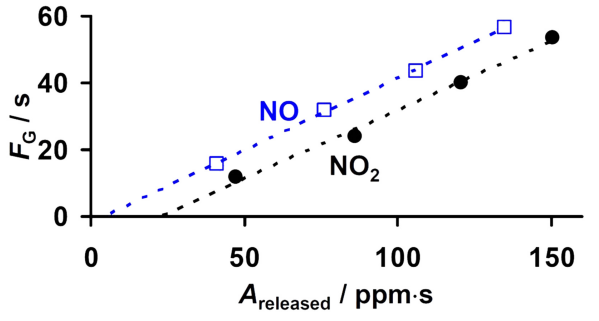

Figure 12. eTPD results of the potassium and manganese containing $\mathrm{NO}_{\mathrm{x}}$ dosimeter after exposure to $8 \mathrm{ppm} \mathrm{NO}$ or $\mathrm{NO}_{2}$ for different $\mathrm{NO}_{2}$ exposure durations $t_{\mathrm{NO}_{2}}$ up to $1000 \mathrm{~s}$ : (a) linear increase of the desorbed amount $A_{\text {released }}$ with $t_{\mathrm{NO}_{2}}$; (b) course of the conductance, $G$, in different loading states upon heating; and (c) linear correlation between $A_{\text {released }}$ and the electrical response, $F_{\mathrm{G}}$ (deviation of $G$ from $G_{0}$ ), during desorption. Reprinted from Groß et al. (2013a), with permission of the authors.

released amount, $A_{\text {released }}$ (measured by a chemiluminescence detector), increases proportionally to the $\mathrm{NO}_{\mathrm{x}}$ exposure time, $t_{\mathrm{NO}_{2} \text {,in }}$, at the fixed $\mathrm{NO}_{\mathrm{x}}$ concentration of $8 \mathrm{ppm}$, indicating a time-constant sorption rate (Fig. 12a). In Fig. 12b, the curves of $\log G$ during heating after different $\mathrm{NO}_{2}$ exposure intervals from 250 to $1000 \mathrm{~s}$ are compared to those without $\mathrm{NO}_{2}$ dosing $\left(\log G_{0}\right.$, after $\left.0 \mathrm{~s} \mathrm{NO} \mathrm{N}_{2}\right)$. The temperature at which all the curves meet, here about $620^{\circ} \mathrm{C}$, represents the end of the nitrate decomposition. Figure 12c clarifies that for $\mathrm{NO}$ or $\mathrm{NO}_{2}$ dosage, the electrical response, $F_{\mathrm{G}}$ (Eq. 3), during thermal regeneration serves as an electrical measure for the former $\mathrm{NO}_{\mathrm{x}}$ loading level, since $F_{\mathrm{G}}$ correlates with $A_{\text {released }}$. Figure 12 reveals that, besides of the real-time and time-continuous detection of the analyte dose during the sorption period, the $\mathrm{NO}_{\mathrm{x}}$ loading state as well as the cumulated $\mathrm{NO}_{\mathrm{x}}$ exposure can also be determined electrically during the short-term thermal release. In this operation mode, the gas dosimeter can be seen as passive sampler with an internal sensor function to determine the sampled analyte dose electrically instead of applying an external subsequent gas analysis in the laboratory. By 
combining these two operation modes (measurement during sorption and desorption), it is expected that the redundant information enables a plausibility consideration of the timeresolved sensor signal (Groß et al., 2013a).

Similarly, the $\mathrm{NH}_{3}$ loading level of zeolites being applied for the selective catalytic reduction (SCR) of $\mathrm{NO}_{\mathrm{x}}$ was electrically investigated during thermal $\mathrm{NH}_{3}$ release by Kubinski et al. (2008) and the Simon group (Rodríguez-González et al., 2008; Rodríguez-González and Simon, 2010; Simons and Simon, 2011, 2012). Kubinski et al. (2008) described a linear correlation between the average alternating current $I_{\text {Average }}$ at a constant applied AC voltage $\left(5 V_{P-P}\right)$ at a frequency of $4 \mathrm{~Hz}$ during the thermal $\mathrm{NH}_{3}$ release and the duration of the previous $\mathrm{NH}_{3}$ exposure of an SCR catalyst-based conductivity sensor (Fig. 13). For reaching a lowly loaded state, the sensor was exposed to a constant $\mathrm{NH}_{3}$ concentration, as indicated in a base gas atmosphere of $5 \% \mathrm{O}_{2}$ and $\sim 1 \% \mathrm{H}_{2} \mathrm{O}$ in $\mathrm{N}_{2}$ for time durations from 0 to $40 \mathrm{~min}$. Measuring $I_{\text {Average }}$ during thermal $\mathrm{NH}_{3}$ release enables the in situ monitoring of the former $\mathrm{NH}_{3}$ loading level with a higher sensitivity compared to those in the sorption mode.

A similar example for the investigation of the electrical properties during release of a chemisorbed gas species was the work of Rossé et al, 1984. They found that a CdSe thin film irreversibly sorbs oxygen and can be thermally regenerated, causing a measurable change in the resistance.

The different operation modes of gas dosimeters are summarized in Fig. 14. As discussed in detail, the cumulated analyte exposure as well as the analyte loading level of the sensitive material can be electrically detected either during sorption (including concentration information from the derivative) (Fig. 14a) or regeneration (Fig. 14b). Due to the correlation between the analyte amount and the sensor signal, it is possible to determine the mean analyte concentration also by the time $\Delta t_{\text {spec }}$ that is needed to reach a defined loading state of the sensor, indicated by a specific signal change $|\mathrm{SR}|_{\text {spec }}$ (Fig. 14c). For instance, the frequency of regeneration might serve as a measure for the analyte concentration. Due to a limited linear measurement range, the regeneration needs to be initiated at a predefined sensor signal before the signal saturates. Further, the time to reach a percolation threshold, $t_{\mathrm{perc}}$, indicated by a steep increase or decrease in the conductivity of the percolation dominated dosimeter, may serve as the measure for the mean concentration (Fig. 14d). For both time-measuring modes, no instantaneous information on the cumulated exposure or the actual concentration is obtained.

\subsection{Gas dosimeters based on percolation effects}

Percolation effects (Ulrich et al., 2004) may modify the sensing characteristics of gas dosimeters, as investigated and described in detail for soot sensors being similar to gas sensors. Several soot sensors for diesel particulate filters consisting of an insulating substrate with electrodes on top have been reported (Ochs et al., 2010; Weigl et al., 2010; Hagen et al.,

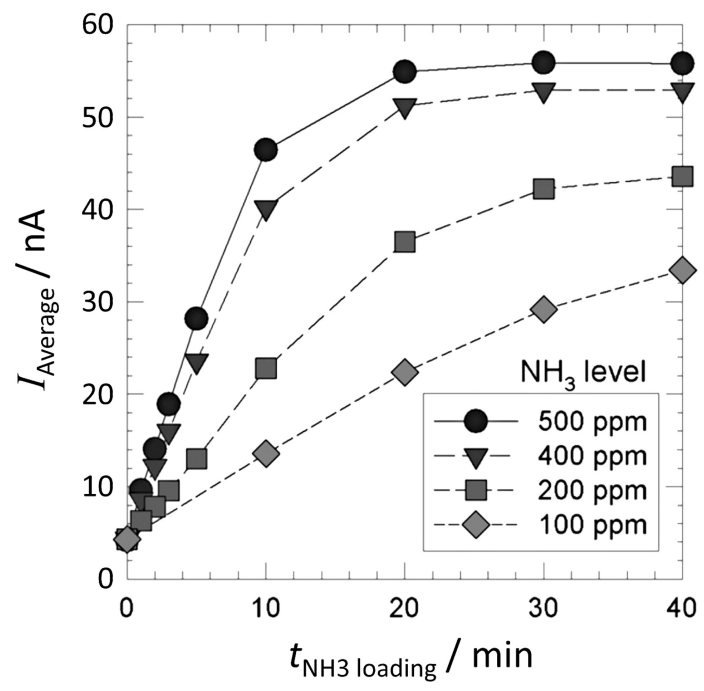

Figure 13. Average current $I_{\text {Average }}$ during heating up to $520^{\circ} \mathrm{C}$ for thermal regeneration of a zeolite-based $\mathrm{NH}_{3}$ sensor depending on

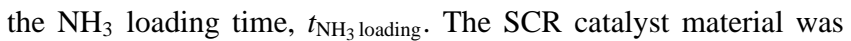
loaded at a temperature of $\sim 267^{\circ} \mathrm{C}$ in a gas stream composed of $5 \% \mathrm{O}_{2}$ and $\sim 1 \% \mathrm{H}_{2} \mathrm{O}$ in $\mathrm{N}_{2}$ containing $\mathrm{NH}_{3}$, as indicated for 0 to 40 min. Adapted from Kubinski and Visser (2008); reprinted with permission from Elsevier.

2010; Kondo et al., 2011; Husted et al., 2012; Bartscherer and Moos, 2013). The resistance between these electrodes is analyzed. It serves as a measure for accumulated soot particles on an insulating support. Figure 15 schematically depicts the formation of conductive pathways for the soot sensing device in its different states of soot loading. The soot deposition is driven by electrophoresis due to the applied voltage, $U$. Soot paths start to grow at the electrodes. From Fig. 15a to $\mathrm{d}$, the amount of deposited conductive soot particles on the substrate surface between the electrodes increases. For the unloaded and lowly soot loaded state, almost no current, $I$, flows and the resistance between the electrodes, $R$, is almost infinite $(R \rightarrow \infty)$. The sensor remains blind until the percolation threshold is reached after an exposure time of $t_{\text {perc }}$. Then, the formed conducting paths cause a fast decrease of the resistance $(R<\infty)$. Further soot accumulation leads to an additional current increase or resistance decrease $(R \downarrow)$. An additional low-conducting layer on top of the electrodes made of a resistive paste may reduce the sensor blind time. Owing to the low conductivity of the added layer, the soot amount can be detected in the accumulation mode without percolation effects (Bartscherer and Moos, 2013). The actual soot concentration can be determined from the percolation time $t_{\text {perc }}$ (time to reach a certain value of $I$ ) (Ochs et al., 2010) or from the slope $\mathrm{d} I / \mathrm{d} t$ (Weigl et al., 2010). As soon as a predefined current is reached, the sensor device is heated, the soot burns off, and after cooling to operation temperature, the regeneration is completed and a new accumulation period starts. 


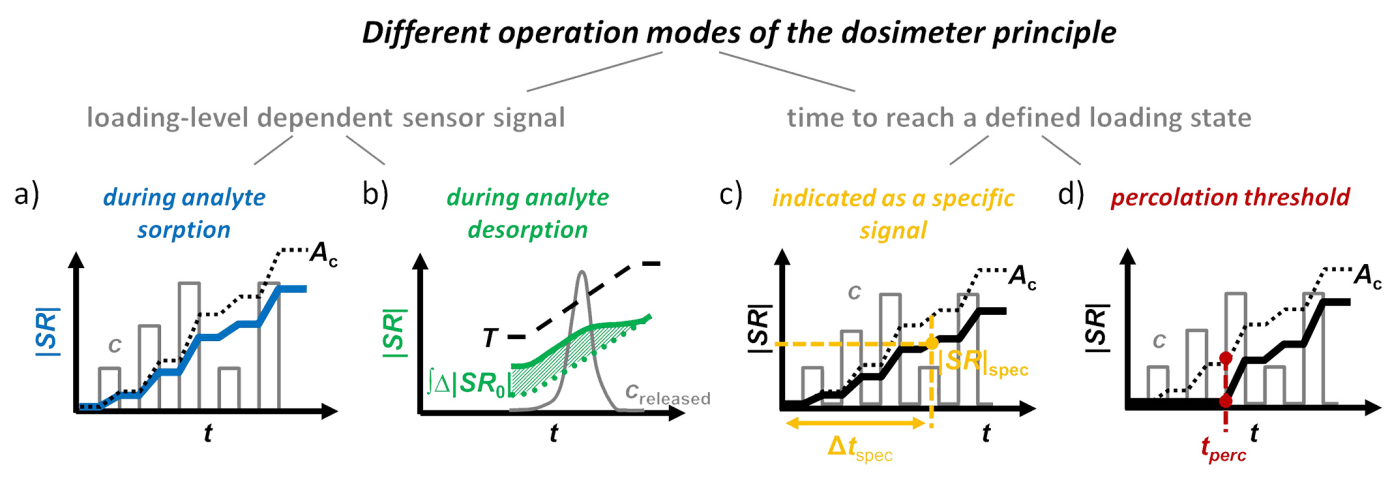

Figure 14. Scheme of the different operation modes of gas dosimeters: consideration of the loading level-dependent sensor signal during (a) analyte sorption and (b) analyte desorption and of the period of time to reach a defined loading state indicated by (c) a specific sensor signal like the end of the linear measurement range, or, e.g., (d) the percolation threshold.

a)

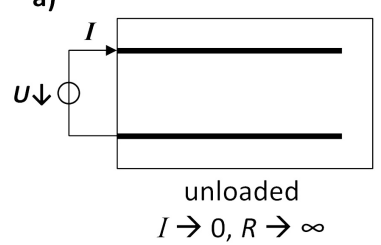

c)

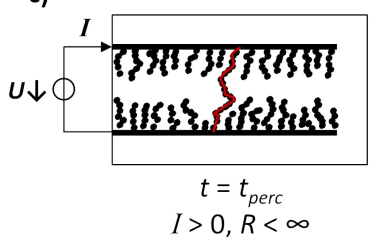

b)

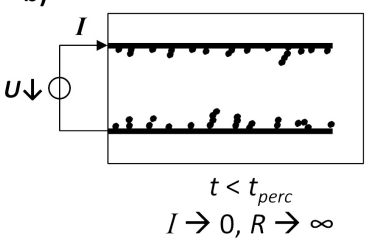

d)

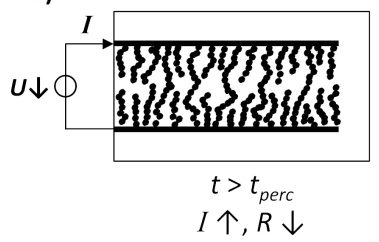

Figure 15. Scheme of percolation-dominated resistive soot detection with planar electrodes on an insulating substrate: (a) regenerated soot sensor with an infinite resistance $R$, (b) sensor covered by a few soot particles below the percolation threshold, (c) sensor at point in time when the percolation threshold $t_{\text {perc }}$ is reached due to a sufficient number of deposited particles forming a conductive pathway with a specific resistance, and (d) more soot particles at the surface, causing a further decrease of $R$.

Another example for dosimeter type gas sensors using percolation effects is given by Hennemann et al. (2012b, c) and Sauerwald et al. (2013). Applying $\mathrm{CuO}$ nanofibers as $\mathrm{H}_{2} \mathrm{~S}$ sensitive materials, the change of conductance of the fibers upon pulsed $\mathrm{H}_{2} \mathrm{~S}$ dosing is measured. When adsorbing $\mathrm{H}_{2} \mathrm{~S}$, the conductance of the fibers increases due to their transition from $\mathrm{CuO}$ to $\mathrm{CuS}$. However, as shown in Fig. 16a, the conductance $G$ does not change during the first $\mathrm{H}_{2} \mathrm{~S}$ pulses, but after reaching the percolation threshold, a conductive pathway of $\mathrm{CuS}$ in the $\mathrm{CuO}$ layer is formed and the conductance increases promptly. Beyond the percolation threshold, the sensor behaves like a $\mathrm{H}_{2} \mathrm{~S}$ integrating gas sensor. Nevertheless, saturation effects deteriorate the sensor signal soon after reaching the percolation threshold. If one plots the re-

ciprocal value of the percolation time $t_{\text {perc }}$ (defined as the time when the percolation threshold is reached, denoted as "switching time" in the work of Hennemann et al., 2012a) as a function of the $\mathrm{H}_{2} \mathrm{~S}$ concentration, Fig. 16b implies a linear dependency, demonstrating clearly that $t_{\text {perc }}$ decreases with increased $\mathrm{H}_{2} \mathrm{~S}$ concentration. Hence, a direct measurement of the actual concentration and dose of $\mathrm{H}_{2} \mathrm{~S}$ is not possible; however, by the evaluation of the switching time the average concentration and the total amount of $\mathrm{H}_{2} \mathrm{~S}$ in a certain period of time can be determined indirectly (Hennemann et al., 2012a).

Similarly, the electrical properties of a Ni-based catalyst pellets were examined by impedance spectroscopy during the exposure to $\mathrm{H}_{2} \mathrm{~S}$. Before sulfur poisoning, the conductance is very low due to the high dispersion of the Ni particles in the catalyst, i.e., the impedance is dominated by the permittivity of the pellet material. With the addition of $\mathrm{H}_{2} \mathrm{~S}$, nickel sulfide forms. Due to the enhanced volume of the nickel sulfides compared to the Ni particles, the distance between the conductive particles diminishes. Reaching the percolation threshold, the conductance increases immediately due to the formation of conductive pathways of nickel sulfides, allowing also dosimeter-type $\mathrm{H}_{2} \mathrm{~S}$ detection (Fremerey et al., 2012).

It should be clear, however, that accumulating percolationtype gas sensors cannot display the instant value directly. Since they act like switches if a certain accumulation level has been reached, however, the time span between two percolation events can be seen as an indicator for the average concentration between the two events.

\section{Suitable materials for accumulating gas sensors}

To find adequate materials in gas dosimeter application, it is necessary to define the required properties of these materials. In general, the following five main criteria were found to be crucial for the proper selection of materials as sensitive 
a)

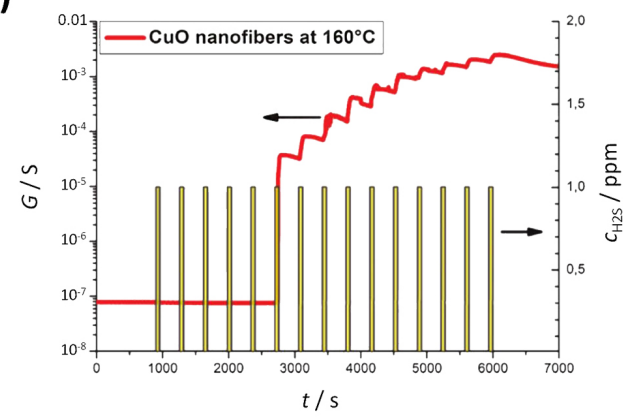

b)

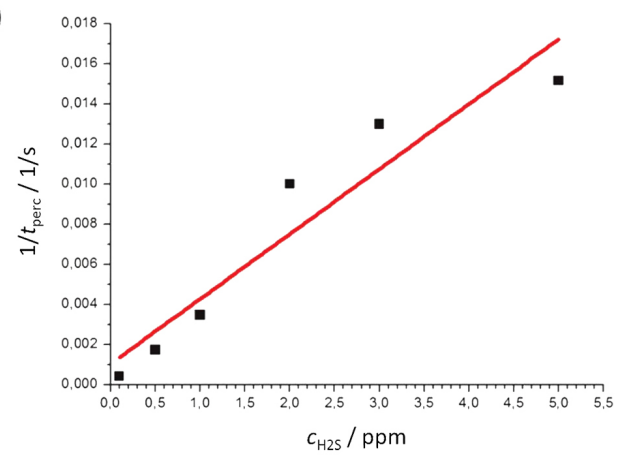

Figure 16. Percolation-dominated $\mathrm{H}_{2} \mathrm{~S}$ detection with $\mathrm{CuO}$ nanofibers at $160^{\circ} \mathrm{C}$ : (a) conductance during consecutive $1 \mathrm{ppm} \mathrm{H}_{2} \mathrm{~S}$ pulses for 1 min each with a sudden increase of the conductance as the percolation threshold is reached, denoted as switching time, (b) correlation between the reciprocal switching time and the $\mathrm{H}_{2} \mathrm{~S}$ concentration. Modified after Hennemann et al. (2012a); reprinted with permission from John Wiley and Sons.

components of gas dosimeters with a linear sensing characteristic (Groß et al., 2012a).

1. Selective sorption of the analyte: only one distinct gas species should accumulate in the sensitive layer, e.g., by chemisorption, including the chemical transformation of the material. To obtain linear sensing characteristics, the sorption rate should be proportional to the current analyte concentration in the gas phase.

2. Strength of sorption: the analyte sorption rate has to exceed largely the desorption rate to ensure accumulation of analyte molecules in the sensitive material without releasing formerly sorbed molecules in the absence of the analyte in the gas atmosphere (i.e., holding capability).

3. At least one measurable electrical property must change with analyte accumulation, e.g., the impedance or the conductivity. The relation between the analyte loading level and the change of the electrical measurand has to be linear.

4. The sorption rate must be independent of the present analyte loading level of the sensitive layer so that no deterioration of the sorption efficiency with time occurs.

5. Ability to actively initiate a regeneration: the sensitive material must be able to release the formerly sorbed analyte molecules from the storage sites under defined conditions that are different from the sorption conditions (e.g., different temperature or gas composition). If there is no possibility to regenerate the storage material, the sensor is a single-use device.

Conductometric gas sensors using the accumulating sensing principle have been reported by several working groups for various analytes and sensitive materials (Sect. 3). The applied materials range from organic semiconductors to metal oxides, zeolites and carbon nanotubes. In the following an overview on the materials is given.

Suitable materials for the accumulation sensing mode are materials that have been successfully applied as storage components, for instance in filters or catalysts, e.g., lean $\mathrm{NO}_{\mathrm{x}}$ traps or selective catalytic reduction (SCR) materials storing $\mathrm{NH}_{3}$. Geupel et al. (2011) applied $\mathrm{NO}_{\mathrm{x}}$ storage catalysts based on alkaline (earth) carbonates as coatings for $\mathrm{NO}_{\mathrm{x}}$ dosimeter operated at temperatures in the range of 300 to $400{ }^{\circ} \mathrm{C}$. However, $\mathrm{BaCO}_{3}$ serves also as a sulfur oxide adsorbing layer on a gas sensor to protect it from sulfur poisoning (Rettig et al., 2003). The irreversible interaction of $\mathrm{SO}_{2}$ with the $\mathrm{NO}_{\mathrm{x}}$ storage catalyst material causes a crosssensitivity of the $\mathrm{NO}_{\mathrm{x}}$ dosimeter but enables $\mathrm{SO}_{2}$ dosimetry (Groß et al., 2012d). Zeolites, being a common class of materials in SCR catalysis due to their $\mathrm{NH}_{3}$ storage capability, are also viable materials as sensitive layers working in the accumulation mode. The gas sorption capacity of zeolites is very high and, due to their special framework structure, they hold a certain shape-selectivity. Upon gas sorption, zeolite materials are able to change their conductivity (Stamires, 1962; Eigenmann et al., 2000; Sahner et al., 2008), making them potential candidates for dosimeter-type sensors. An example for the dosimeter-type conductivity change is proton conducting H-ZSM-5 adsorbing $\mathrm{NH}_{3}$ (Simon et al., 1998; Franke et al., 2003; Kubinski and Visser, 2008). Similar to those microporous zeolites, mesoporous materials might also be of interest, as they have been successfully applied as preconcentrators in gas sensors to enhance the sensitivity by analyte accumulation in the porous material via sorption (Wagner et al., 2013).

Metal oxides also show potential as sensitive layers of gas dosimeters. Hennemann et al. (2012a) showed that $\mathrm{CuO}$ is an appropriate material for the accumulative detection of $\mathrm{H}_{2} \mathrm{~S}$ being dominated by percolation effects. The conductivity of $\mathrm{NiO}$ shows a similar behavior in $\mathrm{H}_{2} \mathrm{~S}$ containing gas atmosphere (Fremerey et al., 2012). Other (transition) metal 
oxides, yet to be applied as sensitive material in conventional gas sensors, should be investigated concerning their suitability as gas dosimeter under modified sensing conditions that allow for irreversible analyte sorption, e.g., $\mathrm{WO}_{3}$ and $\mathrm{Al}$-activated $\mathrm{WO}_{3}$ as $\mathrm{H}_{2} \mathrm{~S}$ dosimeter at room temperature (Reyes et al., 2006) and $\mathrm{SnO}_{2}$ as $\mathrm{O}_{2}, \mathrm{H}_{2} \mathrm{O}$, and $\mathrm{H}_{2}$ dosimeter (Yamazoe et al., 1979). Mathieu et al., 2013, for example, give a broad overview on the sorption of $\mathrm{SO}_{2}$ by various oxides, e.g., $\mathrm{CaO}, \mathrm{TiO}_{2}, \mathrm{CeO}_{2}, \mathrm{MnO}_{2}$ and mixed oxides, meaning metal oxides in association with, e.g., $\mathrm{Al}_{2} \mathrm{O}_{3}$. They also describe the regeneration of the metal oxides by thermal decomposition of the metal sulfates (Mathieu et al., 2013). With regard to the accumulating sensor principle, these materials hold a certain storage capacity, but it has to be clarified whether the $\mathrm{SO}_{2}$ accumulation causes measurably changing electrical properties.

Another class of materials, providing a gas storage capacity that can be monitored by the resistance, are metal oxidecoated carbon nanotubes (Mangu et al., 2010). Varghese et al. (2001) reported impedimetric gas sensors based on $\mathrm{SiO}_{2}$ coated multi-wall carbon nanotubes as sensitive layer, showing the behavior of a conventional gas sensor towards $\mathrm{H}_{2} \mathrm{O}$ (Varghese et al., 2001), $\mathrm{O}_{2}$ and $\mathrm{CO}_{2}$ (Ong et al., 2002), but acting as a dosimeter in presence of $\mathrm{NH}_{3}$ (Varghese et al., 2001; Ong et al., 2002). Single-walled carbon nanotubes with $\mathrm{SnO}_{2}$ coatings were applied by Mubeen et al. (2013) as resistive gas sensors. Their tests with several gases reveal the classical gas sensor response; however the behavior towards $\mathrm{NO}_{2}$ is dosimeter-like.

As already shown, hydrogenated diamond is a well-suited material for the accumulating sensing method to detect $\mathrm{NO}_{2}$ and $\mathrm{NH}_{3}$ due to a $\mathrm{pH}$ change upon electrolytic analyte dissociation in the surface electrolyte layer (Beer et al., 2013; Helwig et al., 2013). The hydrogenated diamond-based sensor can be regenerated thermally by $\mathrm{O}_{3}$ or UV light (Helwig et al., 2007, 2008).

Conductive polymers have already been applied for gas sensing applications. Bai and Shi show an overview on different polymers for gas detection. They described that some of the conductive polymers show an irreversible reaction to certain gases, making them a notable class of materials for gas dosimeters. However, it has to be kept in mind that polymers often show a poor long-term stability (Bai and Shi, 2007; Liu et al., 2012). The conductive polymeric system PEDOT:PSS was applied as a gas sensitive layer by Liu et al. (2012), acting as a classical gas sensor in the presence of $\mathrm{NO}_{\mathrm{x}}$. However, initial tests of Marr et al. (2013) have shown that the conductive copolymer PEDOT:PSS is also a promising material for an accumulating gas sensing device. Their first measurements at room temperature with $\mathrm{NO}_{\mathrm{x}}$ as test gas show a dosimeter-type change of the resistance in presence of $\mathrm{NO}_{\mathrm{x}}$.

Organic compounds also might be suitable materials for the integrating sensing principle. A resistive low-level $\mathrm{NO}_{2}$ dosimeter based on iron (II) phthalocyanine was presented by Shu et al. (2010). Padma et al. (2009) and Brunet et al.
(2001, 2008) reported a $\mathrm{NO}_{2}$ sensitivity of copper phthalocyanine. The Saltzmann reagent was applied in optical sensors for the detection of $\mathrm{O}_{3}$ and $\mathrm{NO}_{2}$ (Tanaka et al., 1998, 1999; Maruo, 2007; Maruo et al., 2009), morpholines for $\mathrm{NO}_{2}$ sensing (Matsuguchi et al., 2005), eosin $\mathrm{Y}$ for $\mathrm{NH}_{3}$ detection via the slope of the drain current of a based OFET (Klug et al., 2013), and naphthyl polyenes to detect organic vapors electrically (Sircar et al., 1983). Their suitability for resistive gas dosimeters should be investigated.

Even metals can be applied as sensitive materials for gas dosimeters: Mattoli et al. (2007) realized a sensing device based on a Au layer for the resistive, cumulative detection of gaseous $\mathrm{Hg}$. Ag was found to be a suitable material for the detection of $\mathrm{H}_{2} \mathrm{~S}$ in the accumulation mode by Angelini et al. (2009) and Chen et al. (2013).

Additionally, Mukherjee et al. (2012) summarizes gas sensor materials interacting reversibly or partly irreversibly with various gases.

As already mentioned in Sect. 2, the temperature strongly influences the gas sensing behavior (Reyes et al., 2006; Andringa et al., 2012; Shu et al., 2012; Brandenburg et al., 2013; Groß et al., 2013a). Since conventional gas sensors are mostly based on metal oxides as sensitive layer and these materials are known to be able to adsorb gases, e.g., $\mathrm{SO}_{2}$ (Mathieu et al., 2013), they might be suitable for applications in a gas dosimeter under modified operation conditions. The desorption of the analyte gas predominates at elevated temperatures if the analyte concentration in the gas phase decreases. The sensor signal changes reversibly, according to the established chemical equilibrium. Hence, the operation of the sensitive materials of conventional gas sensors at lower temperatures might reveal dosimeter-type sensing properties with analyte accumulation due to a reduced desorption rate. Similarly, $\mathrm{BaCO}_{3}$ acts as $\mathrm{NO}_{\mathrm{x}}$ dosimeter at low temperatures (Groß et al., 2013b) but the recovery time after $\mathrm{NO}_{\mathrm{x}}$ sorption can be reduced by increasing the temperature, resulting in a reversible sensing characteristic (Tamaki et al., 1995).

\section{Conclusion and outlook}

The accumulating sensing principle of solid-state gas dosimeters is a promising method in order to elude certain drawbacks of classical metal oxide gas sensors. Dosimetertype gas sensors are well suited for the detection of harmful, toxic gases. This is in accordance with the growing demand for sensing devices that are able to detect lowest analyte concentrations reliably, fast and over a long period of time, particularly in the field of air quality monitoring in workplaces and urban environments. Acting similar to passive samplers, gas dosimeters are able to detect very low concentration levels of gaseous pollutants. However, the dosimeter offers a real-time detection of the analyte dose, according to mean time values in emission and immission legislations. Due to the chemical accumulation of the analyte in 
the sensing material, the error-prone mathematical integration of the concentration-related sensor signal, as is necessary in cases of conventional gas sensors to measure doses, is not needed.

Being affected by several influencing factors, the accumulating sensing principle might be adapted to common gas sensing materials under modified measurement conditions.

This overview shows a number of works applying and describing accumulating sensing behavior, but further investigations regarding the long-term stability of gas dosimeter have to be conducted, especially when the regeneration step is a thermal one. A comparison between classical gas sensors and gas dosimeters lists the advantages and disadvantages of both sensing principle. Nevertheless, different principles have to be tested under same conditions to compare them directly.

Acknowledgements. Ralf Moos thanks the German Research Foundation (DFG) for supporting this work under grant number MO 1060/15-1.

Edited by: M. Penza

Reviewed by: two anonymous referees

\section{References}

Andringa, A.-M., Vlietstra, N., Smits, E. C. P., Spijkman, M.-J., Gomes, H. L., Klootwijk, J. H., Blom, P. W. M., and de Leeuw, D. M.: Dynamics of charge carrier trapping in $\mathrm{NO}_{2}$ sensors based on $\mathrm{ZnO}$ field-effect transistors, Sensor. Actuator. B: Chemical, 171-172, 1172-1179, doi:10.1016/j.snb.2012.06.062, 2012.

Angelini, E., Grassini, S., Neri, A., Parvis, M., and Perrone, G.: Plastic Optic Fiber Sensor for Cumulative Measurements, in: Proceedings of the International Instrumentation and Measurement Technology Conference - I2MTC 2009, Singapore, 5-7 May 2009, 1666-1670, doi:10.1109/IMTC.2009.5168723, 2009.

Bai, H. and Shi, G.: Gas Sensors Based on Conducting Polymers, Sensors, 7, 267-307, doi:10.3390/s7030267, 2007.

Barsan, N., Koziej, D., and Weimar, U.: Metal oxide-based gas sensor research: How to?, Sensor. Actuator. B: Chemical, 121, 1835, doi:10.1016/j.snb.2006.09.047, 2007.

Bartscherer, P. and Moos, R.: Improvement of the sensitivity of a conductometric soot sensor by adding a conductive cover layer, Journal of Sensors and Sensor Systems, 2, 95-102, doi:10.5194/jsss-2-95-2013, 2013.

Beer, S., Helwig, A., Müller, G., Garrido, J., and Stutzmann, M.: Water adsorbate mediated accumulation gas sensing at hydrogenated diamond surfaces, Sensor. Actuator. B: Chemical, 181, 894-903, doi:10.1016/j.snb.2013.02.072, 2013.

Beulertz, G., Geupel, A., Moos, R., Kubinski, D. J., and Visser, J. H.: Accumulating gas sensor principle - how to come from concentration integration to real amount measurements, Procedia Engineering, 25, 1109-1112, doi:10.1016/j.proeng.2011.12.273, 2011.

Beulertz, G., Groß, A., Moos, R., Kubinski, D. J., and Visser, J. H.: Determining the total amount of $\mathrm{NO}_{\mathrm{x}}$ in a gas stream - Advances in the accumulating gas sensor principle, Sensor. Actuator. B: Chemical, 175, 157-162, doi:10.1016/j.snb.2012.02.017, 2012.

Bhalla, V., Singh, H., and Kumar, M.: Facile Cyclization of Terphenyl to Triphenylene: A New Chemodosimeter for Fluoride Ions, Organic Lett., 12, 628-631, doi:10.1021/o1902861b, 2010.

BImSchV 2010, Neununddreißigste Verordnung zur Durchführung des Bundes-Immissionsschutzgesetzes (Verordnung über Luftqualitätsstandards und Emissionshöchstmengen-39. BImSchV). Bundesgesetzblatt Jahrgang 2010, ausgegeben zu Bonn am 5 August 2010, Nr. 40, 1065, 2010.

Brandenburg, A., Kita, J., Groß, A., and Moos, R.: Novel tubetype LTCC transducers with buried heaters and inner interdigitated electrodes as a platform for gas sensing at various high temperatures, Sensor. Actuator. B: Chemical, 189, 80-88, doi:10.1016/j.snb.2012.12.119, 2013.

Brunet, J., Talazac, L., Battut, V., Pauly, A., Blanc, J. P., Germain, J. P., Pellier, S., and Soulier, C.: Evaluation of atmospheric pollution by two semiconductor gas sensors, Thin Solid Films, 391, 308-313, doi:10.1016/S0040-6090(01)01001-X, 2001.

Brunet, J., Garcia Parra, V., Pauly, A., Varenne, C., and Lauron, B.: An optimized gas sensor microsystem for accurate and realtime measurement of nitrogen dioxide at ppb level, Sensor. Actuator. B: Chemical, 134, 632-639, doi:10.1016/j.snb.2008.06.010, 2008.

Chen, R., Morris, H. R., and Whitmore, P. M.: Fast Detection of Hydrogen Sulfide Gas in the ppmv Range with Silver Nanoparticles Films at Ambient Conditions, Sensor. Actuator. B: Chemical, 186, 431-438, doi:10.1016/j.snb.2013.05.075, 2013.

Corcoran, P. and Shurmer, H. V.: An intelligent gas sensor, Sensor. Actuator. A: Physical, 41-42, 192-197, doi:10.1016/09244247(94)80110-X, 1994.

Dasgupta, P. K., Genfa, Z., Poruthoor, S. K., Caldwell, S., Dong, S., and Liu, S.-Y.: High-Sensitive Gas Sensors Based on GasPermeable Liquid Core Waveguides and Long-Path Absorbance Detection, Anal. Chem., 70, 4661-4669, doi:10.1021/ac980803t, 1998.

Directive 2008/50/EC of the European Parliament and of the Council of 21 May 2008 on Ambient Air Quality and Cleaner Air for Europe, Off. J. EU 2008, L152/1, 2008.

Eigenmann, F., Maciejewski, and Baiker, A.: Gas adsorption studied by pulse thermal analysis, Thermochimica Acta, 359, 131-141, doi:10.1016/S0040-6031(00)00516-5, 2000.

Franke, M. E., Simon, U., Moos, R., Knezevic, A., Müller, R., and Plog, C.: Development and working principle of an ammonia gas sensor based on a refined model for solvate supported proton transport in zeolites, Phys. Chem. Chem. Phy., 5, 5195-5198, doi:10.1039/B307502H, 2003.

Fremerey, P., Jess, A., and Moos, R.: Direct in-situ detection of sulfur loading on fixed bed catalysts, in: Proceedings of the 14th International Meeting on Chemical Sensors IMCS 2012, Nuremberg, Germany, 20-23 May 2012, 76-79, doi:10.5162/IMCS2012/1.1.5, 2012.

Geupel, A., Schönauer, D., Röder-Roith, U., Kubinski, D. J., Mulla, S., Ballinger, T. H., Chen, H.-Y., Visser, J. H., and Moos, R.: Integrating nitrogen oxide sensor: A novel concept for measuring low concentrations in the exhaust gas, Sensor. Actuator. B: Chemical, 145, 756-761, doi:10.1016/j.snb.2010.01.036, 2010.

Geupel, A., Kubinski, D. J., Mulla, S., Ballinger, T. H., Chen, H.-Y., Visser, J. H., and Moos, R.: Integrating $\mathrm{NO}_{\mathrm{x}}$ Sensor for Automo- 
tive Exhausts - A Novel Concept, Sensor Letters, 9, 311-315, doi:10.1166/sl.2011.1471, 2011.

Göpel, W.: New materials and transducers for chemical sensors, Sensor. Actuator. B: Chemical, 18-19, 1-21, doi:10.1016/09254005(94)87049-7, 1994.

Groß, A., Beulertz, G., Marr, I., Kubinski, D. J., Visser, J. H., and Moos, R.: Dual Mode $\mathrm{NO}_{\mathrm{x}}$ Sensor: Measuring Both the Accumulated Amount and Instantaneous Level at Low Concentrations, Sensors, 12, 2831-2850, doi:10.3390/s120302831, 2012a.

Groß, A., Richter, M., Kubinski, D. J., Visser, J. H., and Moos, R.: The Effect of the Thickness of the Sensitive Layer on the Performance of the Accumulating $\mathrm{NO}_{\mathrm{x}}$ Sensor, Sensors, 12, 12329 12346, doi:10.3390/s120912329, $2012 \mathrm{~b}$.

Groß, A., Bishop, S. R., Yang, D. J., Tuller, H. L., and Moos, R.: The electrical properties of $\mathrm{NO}_{\mathrm{x}}$-storing carbonates during $\mathrm{NO}_{\mathrm{x}}$ exposure, Solid State Ionics, 225, 317-323, doi:10.1016/j.ssi.2012.05.009, 2012c.

Groß, A., Hanft, D., Beulertz, G., Marr, I., Kubinski, D. J., Visser, J. H., and Moos, R.: The effect of $\mathrm{SO}_{2}$ on the sensitive layer of a $\mathrm{NO}_{\mathrm{x}}$ dosimeter, Sensor. Actuator. B: Chemical, 187, 153-161, doi:10.1016/j.snb.2012.10.039, 2012d.

Groß, A., Kremling, M., Marr, I., Kubinski, D. J., Visser, J. H., Tuller, H. L., and Moos, R.: Dosimeter-Type $\mathrm{NO}_{\mathrm{x}}$ Sensing Properties of $\mathrm{KMnO}_{4}$ and Its Electrical Conductivity during Temperature Programmed Desorption, Sensors, 13, 4428-4449, doi:10.3390/s130404428, 2013a.

Groß, A., Weller, T., Tuller, H. L., and Moos, R.: Electrical conductivity study on $\mathrm{NO}_{\mathrm{x}}$ trap materials $\mathrm{BaCO}_{3}$ and $\mathrm{K}_{2} \mathrm{CO}_{3} / \mathrm{La}-\mathrm{Al}_{2} \mathrm{O}_{3}$ during $\mathrm{NO}_{\mathrm{x}}$ exposure, Sensor. Actuator. B: Chemical, 187, 461470, doi:10.1016/j.snb.2013.01.083, 2013 .

Hagen, G., Feistkorn, C., Wiegärtner, S., Heinrich, A., Brüggemann, D., and Moos, R.: Conductometric Soot Sensor for Automotive Exhausts: Initial Studies, Sensors, 10, 1589-1598, doi:10.3390/s100301589, 2010.

Helwig, A., Müller, G., Weidemann, O., Härtl, A., Garrido, J. A., and Eickhoff, M.: Gas Sensing Interactions at Hydrogenated Diamond Surfaces, IEEE Sensors Journal, 7, 13491353, doi:10.1109/JSEN.2007.905019, 2007.

Helwig, A., Müller, G., Garrido, J. A., and Eickhoff, M.: Gas sensing properties of hydrogen-terminated diamond, Sensor. Actuator. B: Chemical, 133, 156-165, doi:10.1016/j.snb.2008.02.007, 2008.

Helwig, A., Beer, S., and Müller, G.: Breathing mode gas detection, Sensor. Actuator. B: Chemical, 179, 131-139, doi:10.1016/j.snb.2012.07.088, 2013.

Hennemann, J., Sauerwald, T., Kohl, C.-D., Wagner, T., Bognitzki, M., and Greiner, A.: Electrospun copper oxide nanofibers for $\mathrm{H}_{2} \mathrm{~S}$ dosimetry, Phys. Status Solidi A, 209, 911-916, doi:10.1002/pssa.201100588, 2012a.

Hennemann, J., Sauerwald, T., Wagner, T., Kohl, C.-D., Dräger, J., and Russ, S.: Electrospun Copper(II)oxide Fibers as Highly Sensitive and Selective Sensor for Hydrogen Sulfide Utilizing Percolation Effects, in: Proceedings of the 14th International Meeting on Chemical Sensors - IMCS 2012, Nuremberg, Germany, 2023 May 2012, 197-200, doi:10.5162/IMCS2012/2.3.4, 2012b.

Hennemann, J., Sauerwald, T., Wagner, T., Kohl, C.-D., Dräger, J., and Russ, S.: Gassensoren für Schwefelwasserstoff mit integrierender Funktion, in: Proceedings of the XXVI. Messtechnisches Symposium des Arbeitskreises der Hochschullehrer für
Messtechnik, Aachen, Germany, 20-22 September 2012, 5-16, 2012c.

Husted, H., Roth, G., Nelson, S., Hocken, L., Fulks, G., and Racine, D.: Sensing of Particulate Matter for On-Board Diagnosis of Particulate Filters, SAE paper 2012-01-0372, doi:10.4271/2012-010372, 2012.

Jung, W., Sahner, K., Leung, A., and Tuller, H. L.: Acoustic wavebased $\mathrm{NO}_{2}$ sensor: Ink-jet printed active layer, Sensor. Actuator. B: Chemical, 141, 485-490, doi:10.1016/j.snb.2009.07.010, 2009.

Katayama, S., Yamada, N., and Awano, M.: Preparation of alkalineearth metal silicates from gels and their $\mathrm{NO}_{\mathrm{x}}$-adsorption behavior, Journal of the European Ceramic Society, 24, 421-425, doi:10.1016/S0955-2219(03)00211-5, 2004.

Kita, J., Brandenburg, A., Groß, A., and Moos, R.: Novel tube-type LTTC transducers with buried heaters and inner interdigitated electrodes for high-temperatures gas sensors, Proc. Eng., 47, 6063, doi:10.1016/j.proeng.2012.09.084, 2012.

Klug, A., Denk, M., Bauer, T., Sandholzer, M., Scherf, U., Slugovc, C., and List, E. J. W.: Organic field-effect transistor based sensors with sensitive gate dielectrics used for lowconcentration ammonia detection, Organic Electronics, 14, 500 504, doi:10.1016/j.orgel.2012.11.030, 2013.

Kohl, D.: Function and applications of gas sensors, J. Phys. D: Applied Physics, 34, R125-R149, doi:10.1088/00223727/34/19/201, 2001.

Kondo, A., Yokoi, S., Sakurai, T., Nishikawa, S., Egami, T., Tokuda, M., and Sakuma, T.: New Particulate Matter Sensor for On Board Diagnosis, SAE paper 2011-01-0302, doi:10.4271/201101-0302, 2011.

Kubinski, D. J. and Visser J. H.: Sensor and method for determining the ammonia loading of a zeolite SCR catalyst, Sensor. Actuator. B: Chemical, 130, 425-429, doi:10.1016/j.snb.2007.09.007, 2008.

Li, J., Lu, Y., Ye, Q., Cinke, M., Han, J., and Meyyappan, M.: Carbon Nanotube Sensors for Gas and Organic Vapor Detection, Nano Letters, 3, 929-933, doi:10.1021/n1034220x, 2003.

Liu, X., Cheng, S., Liu, H., Hu, S., Zhang, D., and Ning, H.: A Survey on Gas Sensing Technology, Sensors, 12, 9635-9665, doi:10.3390/s120709635, 2012.

Mangu, R., Rajaputra, S., Clore, P., Qian, D., Andrews, R., and Singh, V. P.: Ammonia sensing properties of multiwalled carbon nanotubes embedded in porous alumina templates, Materials Science and Engineering B, 174, 2-8, doi:10.1016/j.mseb.2010.03.003, 2010.

Marr, I., Stöcker, T., and Moos, R.: Resistives Gasdosimeter auf Basis von PEDOT:PSS zur Detektion von NO und $\mathrm{NO}_{2}$, in: Proceedings of the 11th Dresdner SensorSymposium, Dresden, Germany, 9-11 December 2013, 317-320, doi:10.5162/11dss2013/F3, 2013.

Martin, S. J., Frye, G. C., Spates, J. J., and Butler, M. A.: Gas Sensing with Acoustic Devices, in: Proceedings of the IEEE Ultrasonics Symposium 1996, 1, San Antonio, Texas/USA, 3-6 November 1996, 423-434, doi:10.1109/ULTSYM.1996.584005, 1996.

Maruo, Y. Y.: Measurement of ambient ozone using newly developed porous glass sensor, Sensor. Actuator. B: Chemical, 126, 485-491, doi:10.1016/j.snb.2007.03.041, 2007.

Maruo, Y. Y., Kunioka, T., Akaoka, K., and Nakamura, J.: Development and evaluation of ozone detection paper, Sensor. Actua- 
tor. B: Chemical, 135, 575-580, doi:10.1016/j.snb.2008.09.016, 2009.

Mathieu, Y., Tzanis, L., Soulard, M., Patarin, J., Vierling, M., and Molière, M.: Adsorption of $\mathrm{SO}_{\mathrm{x}}$ by oxide materials: A review, Fuel Proc. Technol., 114, 81-100, doi:10.1016/j.fuproc.2013.03.019, 2013.

Matsuguchi, M., Kadowaki, Y., and Tanaka, M.: A QCM-based $\mathrm{NO}_{2}$ gas detector using morpholine-functional cross-linked copolymer coatings, Sensor. Actuator. B: Chemical, 108, 572575, doi:10.1016/j.snb.2004.11.044, 2005.

Mattoli, V., Mazzolai, B., Raffa, V., Mondini, A., and Dario, P.: Design of a new real-time dosimeter to monitor personal exposure to elemental gaseous mercury, Sensor. Actuator. B: Chemical, 123, 158-167, doi:10.1016/j.snb.2006.08.004, 2007.

Moos, R., Geupel, A., Visser, J. H., and Kubinski, D. J.: Vorrichtung und Verfahren zur Detektion einer Menge einer Gaskomponente, German Patent Application, DE 102010023523 A1, 2010.

Moos, R., Beulertz, G., Geupel, A., Visser, J. H., and Kubinski, D. J.: Vorrichtung und Verfahren zur Detektion der Menge und der Konzentration einer Gaskomponente, German Patent Application, DE 102012206788 A1, 2012.

Mubeen, S., Lai, M., Zhang, T., Lim, J.-H., Mulchandani, A., Deshusses, M. A., and Myung, N. V.: Hybrid tin oxide-SWNT nanostructures based gas sensor, Electrochimica Acta, 92, 484490, doi:10.1016/j.electacta.2013.01.029, 2013.

Mukherjee, K., Gaur, A. P. S., and Majumder, S. B.: Investigations on irreversible- and reversible-type gas sensing for $\mathrm{ZnO}$ and $\mathrm{Mg}_{0.5} \mathrm{Zn}_{0.5} \mathrm{Fe}_{2} \mathrm{O}_{4}$ chemi-resistive sensors, J. Phys. D: Applied Physics, 45, 505306, doi:10.1088/00223727/45/50/505306, 2012.

Nieuwenhuizen, M. S. and Harteveld, J. L. N.: Studies on a surface acoustic wave (SAW) dosimeter sensor for organophosphorous nerve agents, Sensor. Actuator. B: Chemical, 40, 167-173, doi:10.1016/S0925-4005(97)80257-2, 1997.

Ochs, T., Schittenhelm, H., Genssle, A., and Kamp, B.: Particulate matter sensor for on board diagnostics (OBD) of diesel particulate filters (DPF), SAE paper 2010-01-0307, doi:10.4271/201001-0307, 2010.

Ong, K. G., Zeng, K, and Grimes, C. A.: A Wireless, Passive Carbon Nanotube-Based Gas Sensor, IEEE Sensors Journal, 2, 82-88, doi:10.1109/JSEN.2002.1000247, 2002.

Padilla, M., Perera, A., Montoliu, I., Chaudry, A., Persaud, K., and Marco, S.: Drift compensation of gas sensor array data by Orthogonal Signal Correction, Chemometrics and Intelligent Laboratory Systems, 100, 28-35, doi:10.1016/j.chemolab.2009.10.002, 2010.

Padma, N., Joshi, A., Singh, A., Deshpande, S. K., Aswal, D. K., Gupta, S. K., and Yakhmi, J. V.: $\mathrm{NO}_{2}$ sensors with room temperature operation and long term stability using copper phthalocyanine thin films, Sensor. Actuator. B: Chemical, 143, 246-252, doi:10.1016/j.snb.2009.07.044, 2009.

Rettig, F., Moos, R., and Plog, C.: Sulfur adsorber for thick-film exhaust gas sensors, Sensor. Actuator. B: Chemical, 93, 36-42, doi:10.1016/S0925-4005(03)00334-4, 2003.

Reyes, L. F., Hoel, A., Saukko, S., Heszler, P., Lantto, V., and Granqvist, C. G.: Gas sensor response of pure and activated $\mathrm{WO}_{3}$ nanoparticle films made by advanced reactive gas deposition, Sensor. Actuator. B: Chemical, 117, 128-134, doi:10.1016/j.snb.2005.11.008, 2006.
Roadman, M. J., Scudlark, J. R., Meisinger, J. J., and Ullman, W. J.: Validation of Ogawa passive samplers for the determination of gaseous ammonia concentrations in agricultural settings, Atmos. Environ., 37, 2317-2325, doi:10.1016/S1352-2310(03)00163-8, 2003.

Rodríguez-González, L. and Simon, U.: $\mathrm{NH}_{3}$-TPD measurements using a zeolite-based sensor, Measurement Science and Technology, 21, 027003, doi:10.1088/0957-0233/21/2/027003, 2010.

Rodríguez-González, L., Rodríguez-Castellón, E., Jiménez-López, A., and Simon, U.: Correlation of TPD and impedance measurements on the desorption of $\mathrm{NH}_{3}$ from zeolite H-ZSM-5, Solid State Ionics, 179, 1968-1973, doi:10.1016/j.ssi.2008.06.007, 2008.

Rossé, G., Raoult, F., and Fortin, B.: Regeneration of CdSe Thin Films After Oxygen Chemisorption, Thin Solid Films, 111, 175181, doi:10.1016/0040-6090(84)90485-1, 1984.

Sahner, K., Hagen, G., Schönauer, D., Reiß, S., and Moos, R.: Zeolites - Versatile materials for gas sensors, Solid State Ionics, 179, 2416-2423, doi:10.1016/j.ssi.2008.08.012, 2008.

Sasaki, D. Y., Singh, S., Cox, J. D, and Pohl, P. I.: Fluorescence detection of nitrogen dioxide with perylene/PMMA thin films, Sensor. Actuator. B: Chemical, 72, 51-55, doi:10.1016/S09254005(00)00632-8, 2001.

Sauerwald, T., Hennemann, J., Kohl, C.-D., Wagner, T., and Russ, S.: $\mathrm{H}_{2} \mathrm{~S}$ detection utilizing percolation effects in copper oxide, in: Proceedings of Sensor 2013, Nuremberg, Germany, 14-16 May 2013, E6.4, doi:10.5162/sensor2013/E6.4, 2013.

Schütze, A., Pieper, N., and Zacheja, J.: Quantitative ozone measurement using a phthalocyanine thin-film sensor and dynamic signal evaluation, Sensor. Actuator. B: Chemical, 23, 215-217, doi:10.1016/0925-4005(94)01281-L, 1995.

Seethapathy, S., Górecki, T., and Li, X.: Passive sampling in environmental analysis, J. Chromatogr. A, 1184, 234-253, doi:10.1016/j.chroma.2007.07.070, 2008.

Semancik, S., Cavicchi, R. E., Wheeler, M. C., Tiffany, J. E., Poirier, G. E., Walton, R. M., Suehle, J. S., Panchapakesan, B., and DeVoe, D. L.: Microhotplate platforms for chemical sensor research, Sensor. Actuator. B: Chemical, 77, 579-591, doi:10.1016/S0925-4005(01)00695-5, 2001.

Shu, J. H.: Passive Chemiresistor Sensor Based on Iron (II) Phthalocyanine Thin Films for Monitoring of Nitrogen Dioxide, Dissertation, Auburn University, Auburn, Alabama/USA, 13 December 2010.

Shu, J. H., Wikle, H. C., and Chin, B. A.: Passive chemiresistor sensor based on iron (II) phthalocyanine thin films for monitoring of nitrogen dioxide, Sensor. Actuator. B: Chemical, 148, 498503, doi:10.1016/j.snb.2010.05.017, 2010.

Shu, J. H., Wikle, H. C., and Chin, B. A.: Passive Detection of Nitrogen Dioxide Gas by Relative Resistance Monitoring of Iron (II) Phthalocyanine Thin Films, IEEE Sensors Journal, 11, 5661, doi:10.1109/JSEN.2010.2051024, 2011.

Simon, I., Bârsan, N., Bauer, M., and Weimar, U.: Micromachined metal oxide gas sensors: opportunities to improve sensor performance, Sensor. Actuator. B: Chemical, 73, 1-26, doi:10.1016/S0925-4005(00)00639-0, 2001.

Simon, U., Flesch, U., Maunz, W., Müller, R., and Plog, C.: The effect of $\mathrm{NH}_{3}$ on the ionic conductivity of dehydrated zeolites $\mathrm{Na}$ beta and $\mathrm{H}$ beta, Microporous and Mesoporous Materials, 21, 111-116, doi:10.1016/S1387-1811(97)00056-5, 1998. 
Simons, T. and Simon, U.: Zeolite H-ZSM-5: A Microporous Proton Conductor for the in situ Monitoring of $\mathrm{DeNO}_{\mathrm{x}}-\mathrm{SCR}$, in: Proceedings of the Materials Research Society Spring Meeting 2011, 1330, San Francisco, California/USA, 25-29 April 2011, mrss11-1330-j01-03-k03-03, doi:10.1557/opl.2011.1337, 2011.

Simons, T. and Simon, U.: Zeolites as nanoporous, gas-sensitive materials for in situ monitoring of $\mathrm{DeNO}_{\mathrm{x}}-\mathrm{SCR}$, Beilstein Journal of Nanotechnology, 3, 667-673, doi:10.3762/bjnano.3.76, 2012.

Sircar, A., Mallik, B., and Misra, T. N.: Effect of Adsorption of Vapours on the Electrical Conductivity of a Series of Some Naphthyl Polyenes: Adsorption and Desorption Kinetics, J. Phys. Chem. Solids, 44, 401-405, doi:10.1016/0022-3697(83)900677, 1983.

Small IV, W., Maitland, D. J., Wilson, T. S., Bearinger, J. P., Letts, S. A., and Trebes, J. E.: Development of a prototype optical hydrogen gas sensor using a getter-doped polymer transducer for monitoring cumulative exposure: Preliminary results, Sensor. Actuator. B: Chemical, 139, 375-379, doi:10.1016/j.snb.2009.03.020, 2009.

Stamires, D. N.: Effect of Adsorbed Phases on the Electrical Conductivity of Synthetic Crystalline Zeolites, J. Chem. Phys., 36, 3174-3181, doi:10.1063/1.1732446, 1962.

Tamaki, J., Fujimori, K., Miura, N., and Yamazoe, N.: Sensing characteristics of semiconductor barium carbonate sensor to nitrogen oxides at elevated temperature, in: Proceedings of the 2nd East Asian Conference on Chemical Sensors, Xian, China, 5-8 October 1995,1995

Tanaka, T., Ohyama, T., Maruo, Y. Y., and Hayashi, T.: Coloration reactions between $\mathrm{NO}_{2}$ and organic compounds in porous glass for cumulative gas sensor, Sensor. Actuator. B: Chemical, 47, 65-69, doi:10.1016/S0925-4005(98)00051-3, 1998.

Tanaka, T., Guilleux, A., Ohyama, T., Maruo, Y. Y., and Hayashi, T.: A ppb-level $\mathrm{NO}_{2}$ gas sensor using coloration reactions in porous glass, Sensor. Actuator. B: Chemical, 56, 247-253, doi:10.1016/S0925-4005(99)00185-9, 1999.

Ulrich, M., Bunde, A., and Kohl, C.-D.: Percolation and gas sensitivity in nanocrystalline metal oxide films, Appl. Phys. Lett., 85, 242-244, doi:10.1063/1.1769071, 2004.
Varghese, O. K., Kichambre, P. D., Gong, D., Ong, K. G., Dickey, E. C., and Grimes, C. A.: Gas sensing characteristics of multiwall carbon nanotubes, Sensor. Actuator. B: Chemical, 81, 32 41, doi:10.1016/S0925-4005(01)00923-6, 2001.

Varshney, C. K. and Singh, A. P.: Passive Samplers for $\mathrm{NO}_{\mathrm{x}}$ Monitoring: A Critical Review, The Environmentalist, 23, 127-136, doi:10.1023/A:1024883620408, 2003.

Wagner, T., Haffer, S., Weinberger, C., Klaus, D., and Tiemann, M.: Mesoporous materials as gas sensors, Chem. Soc. Rev., 42, 4036-4053, doi:10.1039/c2cs35379b, 2013.

Weigl, M., Roduner, C., and Lauer, T.: Particle-Filter-OnboardDiagnosis by Means of a Soot-Sensor Downstream of the Particle-Filter, in: Proceedings of the $6^{\text {th }}$ International Exhaust Gas and Particulate Emissions Forum, Ludwigsburg, Germany, 9-10 March 2010, 62-69, 2010.

Williams, D. E.: Semiconducting oxides as gas-sensitive resistors, Sensor. Actuator. B: Chemical, 57, 1-16, doi:10.1016/S09254005(99)00133-1, 1999.

Yamazoe, N.: Toward innovations of gas sensor technology, Sensor. Actuator. B: Chemical, 108, 2-14, doi:10.1016/j.snb.2004.12.075, 2005.

Yamazoe, N. and Shimanoe, K.: Overview of Gas Sensor Technology, in: Science and Technology of Chemiresistor Gas Sensors, edited by: Aswal, D. K. and Gupta, S. K., Nova Science Publishers Inc., New York, 2007.

Yamazoe, N., Fuchigami, J., Kishikawa, M., and Seiyama, T.: Interactions of Tin Oxide Surface with $\mathrm{O}_{2}, \mathrm{H}_{2} \mathrm{O}$ and $\mathrm{H}_{2}$, Surface Science, 86, 335-344, doi:10.1016/0039-6028(79)90411-4, 1979.

Yamazoe, N., Sakai, G., and Shimanoe, K.: Oxide Semiconductor Gas Sensors, Catalysis Surveys from Asia, 7, 63-75, doi:10.1023/A:1023436725457, 2003. 